$$
\begin{aligned}
& \text { حق الأقاليم الفدرالية في الاستقلال } \\
& \text { - إقليم كوردستان إنموذجاً - } \\
& \text { إبراهيم محمد صالح } \\
& \text { كلية القانون والعلوم السياسية، جامعة دهوك، إقليم كوردستان- العراق } \\
& \text { (تاريخ استلام البحث: } 30 \text { تشرين الاول، 2017، تاريخ القبول بالنشر: : 11 كانون الاول، 2017) }
\end{aligned}
$$

الخلاصة

يعد موضوع بحثنا من المواضيع الدستورية المهمة جداً في إطار الدولة الفدرالية، إذ يحاول البحث تسليط الضوء على حق الأقاليم الفدرالية

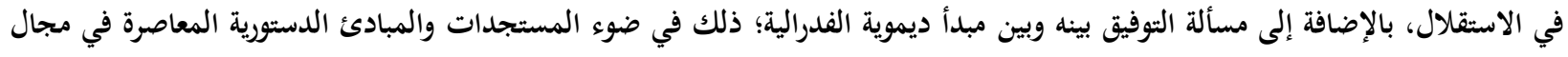

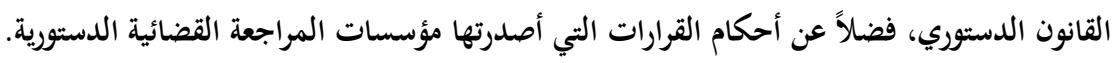

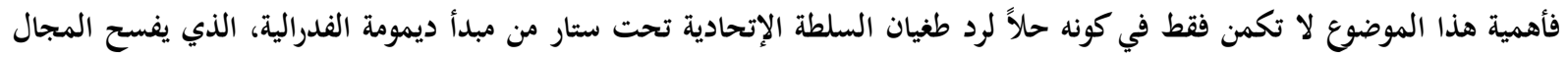

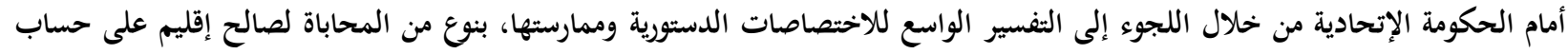

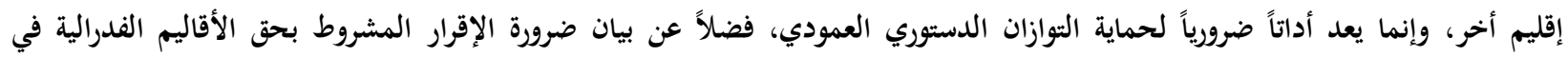

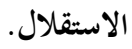

ولكي تشمل هذا البحث كل المسائل والأفكار التي تتعلق بموضوعه فقسمته على ثلاثة مباحث، وقدمت له مطلب تمهيدي بغية بيان مفهوم حق الإقليم الفدرالي في الاستقلال وتميزه مما يختلط به من مفاهيم ولعل من أهم المصطلحات التي تتلداخل معله هو مصطلح الإبطال "Nullification" و مصطلح الإنفصال "Secession".

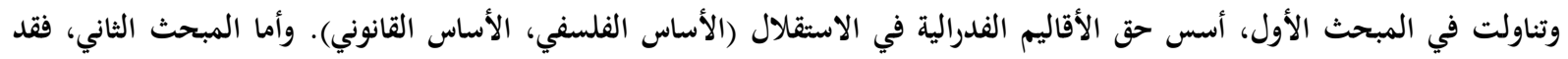

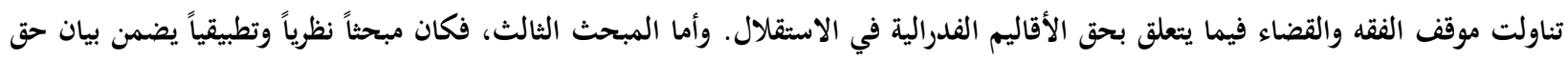

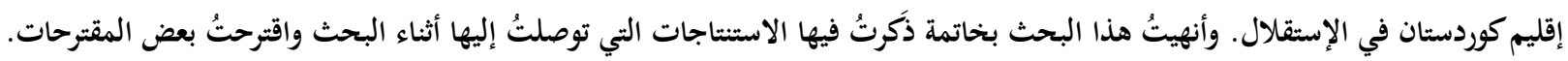

مسألة سلب الاختصاصات من خلال اللجوء إلى التفسير الواسع للنصوص الدستورية سواء من قبل الحكومة الاتحادية والإبحاه نحو الفدرالية المركزية المتشددة وربما تحويلها إلى دولة بسيطة أم من قبل حكومات الإقليمية والاتجاه نخو الفدرالية

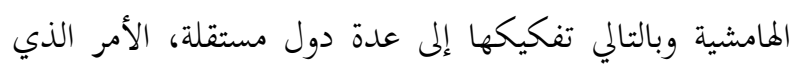

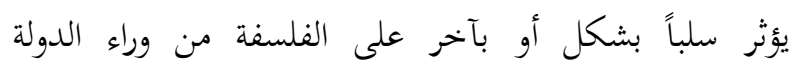

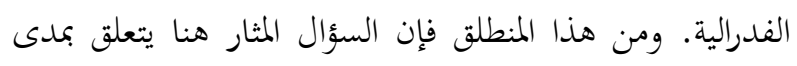
صلاحية الأقاليم الفدرالية في الاستقلال في ظل هذه هلئل الحالة

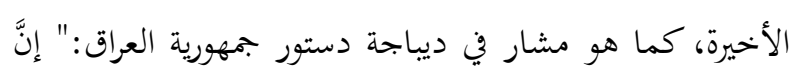

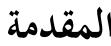

يعد موضوع حق الأقاليم الفدرالية في الاستقلال من المواضيع الدستورية الشائكة في إطار الدولة الفدرالية، حيث يثير عدة مسائل جوهرية منها ما يتعلق بأساسه الفلسفي والعملي

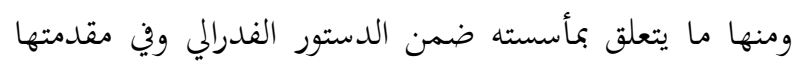
مسألة التوفيق بينه وبين مبدأ ديموية الفدرالية، ومنها ما يتعلق ئقل بأثر الممارسات الدستورية وعلى رأسها مسألة أثر انتهاك

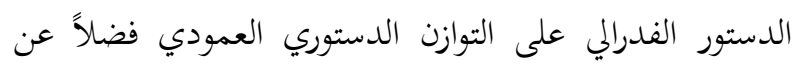


سواه من المصطلحات ثانياً، وهذا ما يشكل مدار البحث في هذا المطلب التمهيدي، وعلى النحو الأتي: الفرع الأول: تعريفه

الدولة الفدرالية بصورة عامة تعني:" منظمة إجتماعية سياسية تقسم فيها سلطة الحكم ما بين حكومات الأقاليم

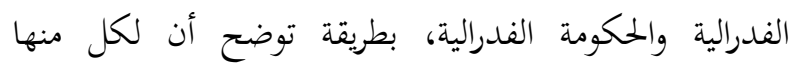
إختصاصات معينة التي تتمكن فيها أن تصدر القرارات النهائية بدون الرجوع إلى الأخرى" (1). البدهي أنه توجد في الدولة الدري الفرولة الفرالية حكومة إتحادية

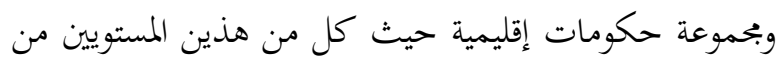

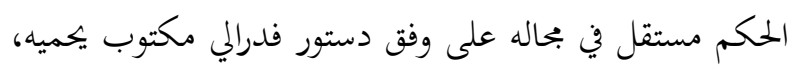

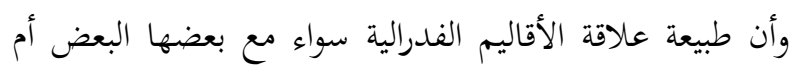
مع الحكومة الفدرالية بذاها تتمثل في العلاقة الفدرالية بأعتبارها مناط المركز الدستوري لككال المستويين من الحكم الفدرالي والإقليمي. ويعد المركز الفدرالي مظهراً من مظاهر حق تقرير المصير، ولمائه

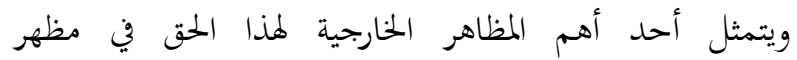
الاستقلال التام، أي صلاحية الإقليم الفدرالي في تغير طبيعة علاقته الفدرالية مع الحكومة الإتحادية بطبيعة العلاقة الدولية، بمعنى تحرير الإقليم الفيدرالي من علاقته الدستورية الفيدرالية والتي

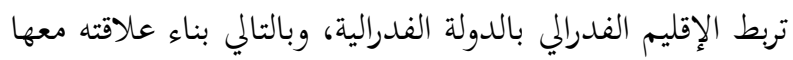

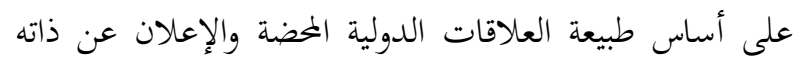
دولة مستقلة ذات سيادة كاملة؛ ذلك بالوسائل السلمية

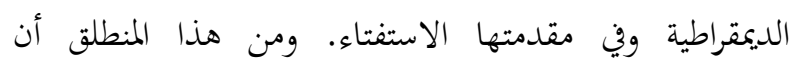
إستقلال الإقليم الفدرالي لا يعني إنفصاله أو إنعزاله من الدولة الفدرالية، وإنما هو إجراء تحول في طبيعة العلاقة بينها وبين إقليم من أقاليمها الفدرالية بغية إصلاح مخرجات تلك إحراء العلاقة، فالاستقلال يعني أن يمارس الدول حقوقها السيادية وتصرف إنهات شؤوها الداخلية والخارجية بحرية كاملة وبمحض الختيارها (2). وتأسيساً على ما تقدم يمكن تعريف حق الأقاليم الفدرالية في

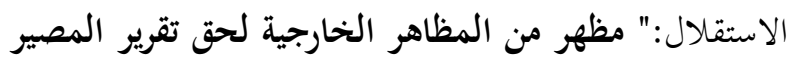

الالتزامَ بهذا الدُستور يَهَفَظُ للعراقِ إتحادَهُ الحُرِ شَعْبَاً وأْرضَاً

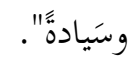

فأن أهمية موضوع حق الأقاليم الفدرالية في الاستقلال لا تكمن فقط في كونه حلاً لرد طغيان السلطة تحت ستار من مبدأ ديمومة الفدرالية وإنما يعد وسيلة ضرورية لحماية التوازان

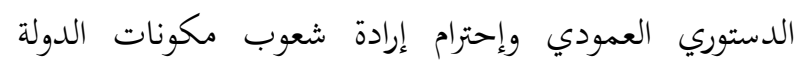

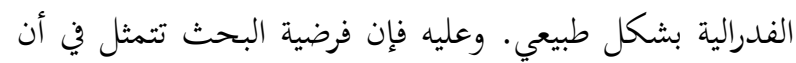
دور الدستور الفدرالي فيما يتعلق بتنظيم حق الأقاليم الفدرالية

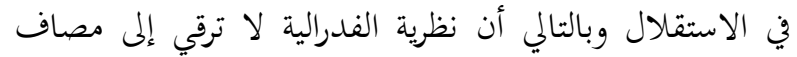
كمال فلسفتها في تحقيق التوازن الدستوري فيما يتعلق بالتوزيع العمودي لسلطة الحكم بين الحكومة الإتحادية وحكومات

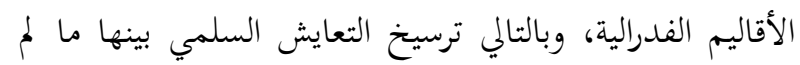
تتبنى فلسفتها بادئ ذي بدء على قاعدة التوفيق بين حق بقئ الأقاليم الفدرالية في الاستقلال ومبدأ ديمومة الفدرالية. وفي ضوء باءئي ما تقدم، ولكي تشمل البحث كل المسائل والأفكار التي تتعلق

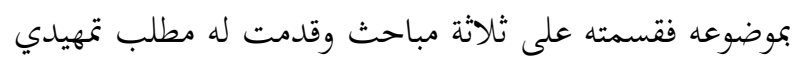
بغية بيان مفهوم حق الإقليم الفدرالي في الاستقلال وتميزه مما يختلط به من مفاهيم ولعل من أهم المصطلحات التي تتداخل

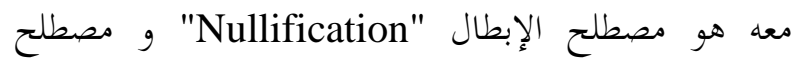
الإنفصال "Secession". وتناولت في المبحث الأول، أسس ترس حق الأقاليم الفدرالية في الاستقلال (الأساس الفلسفي، الأساس القانوني). وأما المبحث الثاني، فقد تناولت موقف الفقه والقضاء فيما يتعلق بكق الأقاليم الفدرالية في الاستقلال. وأما

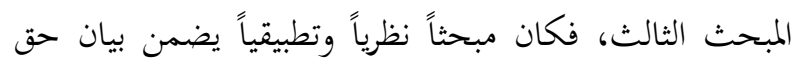
إقليم كوردستان في الإستقلال. وأفيتُ هذا البحث بخاتمة ذكَرتُ فيها الاستنتاجات والمقترحات.

\section{المطلب التمهيدي: مفهوم حق الأقاليم الفيدرالية في الاستقلال}

يقتضينا البحث في مفهوم حق الأقاليم الفيدرالية في

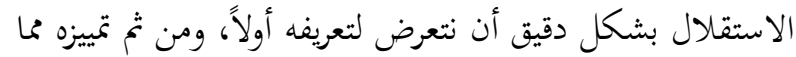




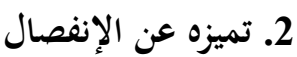

يقصد بالإنفصال (4) خروج جزء من إقليم الدولة عن سيادة

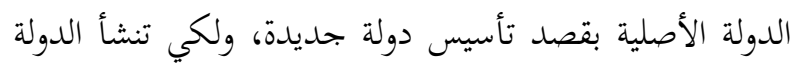
الجديدة يجب إن تكون قد استجمعت كافة عناصر الدولة

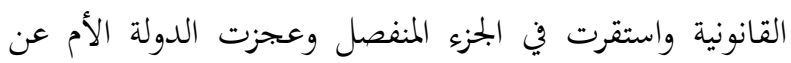

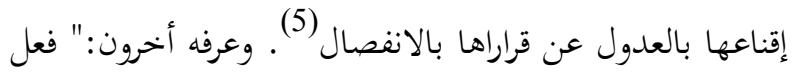

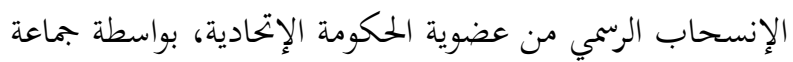

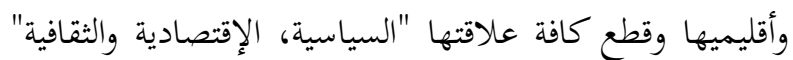

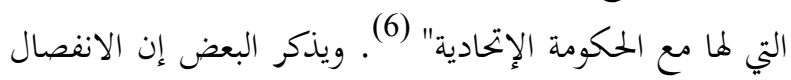

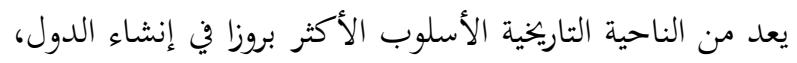

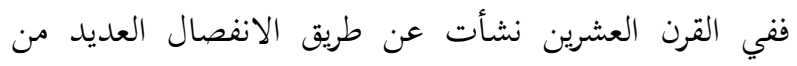

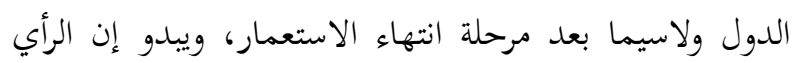

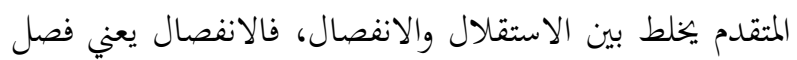

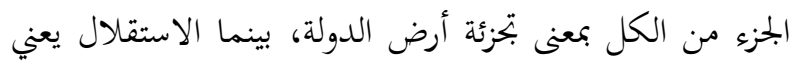

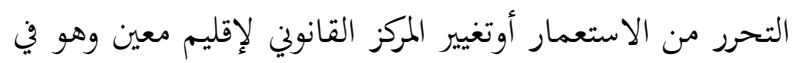

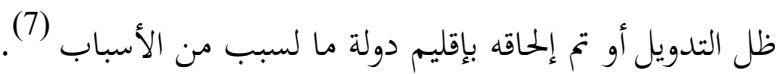

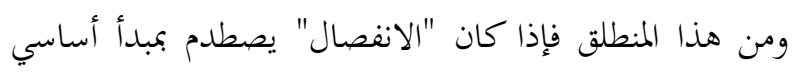

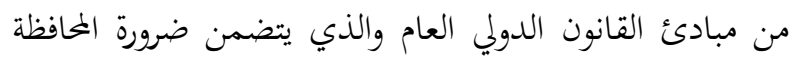

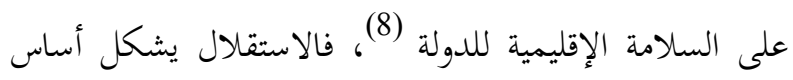
الشرعية الدولية ويتجسد في مبدأ أساسي من المبادئ المقررة في

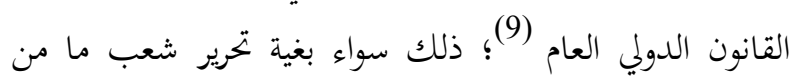

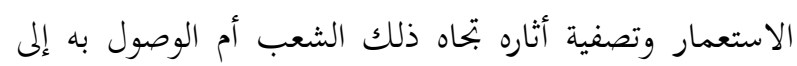
المستوى السياسي والاقتصادي والاجتماعي الذي يستطع فيه

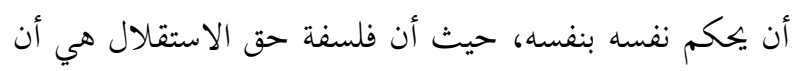
لا تحكم إي شعب إلا بإرادةا، وعليه يمكن القول أن الانفصال

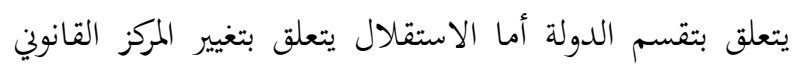

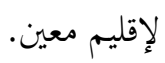

\section{المبحث الأول: أسس حق الأقاليم الفدرالية في الاستقلال}

يتمتع بمقتضاه الإقليم الفدرالي بمكنة تغير طبيعة علاقته الفدرالية مع الحكومة الإتحادية بطبيعة العلاقات الدولية المحضة والإعلان عن ذاته دولة مستقلة ذات سيادة كاملة؛

ذلك بالوسائل السلمية الديمقراطية ".

الفرع الثاني: تمييزه مما يختلط بها من مفاهيم للوقوف على مفهوم حق الأقاليم الفدرالية في الاستقلال

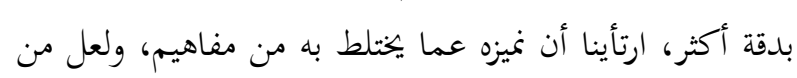

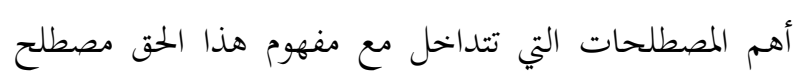

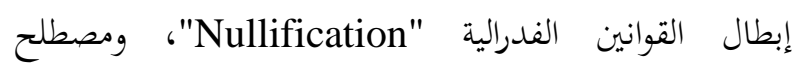
الإنفصال من الفدرالية "Secession".

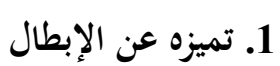
الإبطال يعني الإقرار للأقاليم الفدرالية بممارسة حقها في الإلئ الإنفصال عن الدولة الفدرالية وعدم العمل بالدستور الفدرالي كما تشاء ومتى ما تريد؛ ذلك على أساس أن الأقاليم الفدرالية

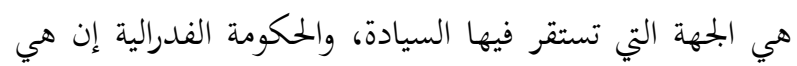

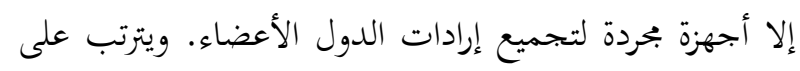

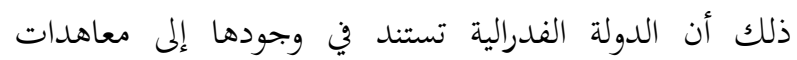

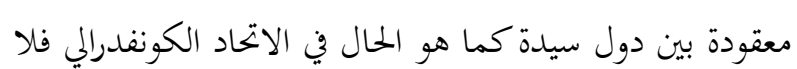

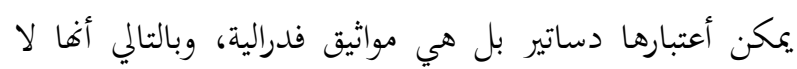

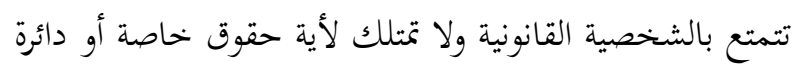

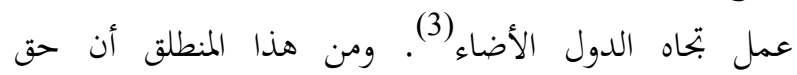

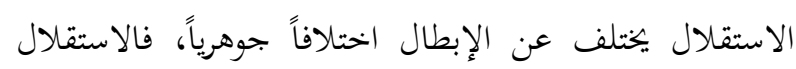

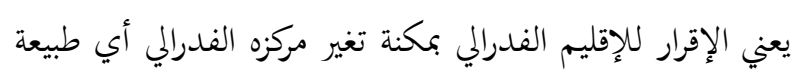

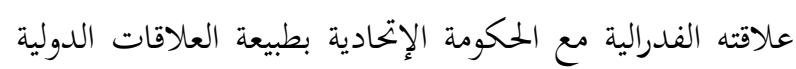
المخضة والإعلان عن ذاته دولة مستقلة ذات سيادة كاملة؛ ذلك الكادية

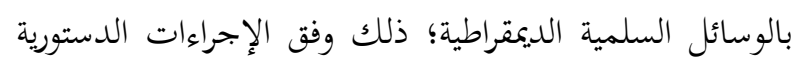

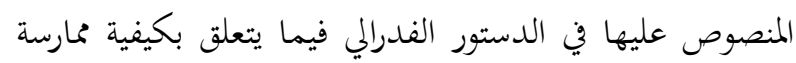

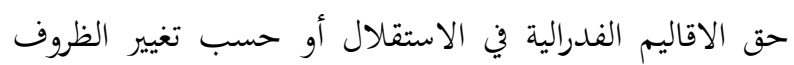

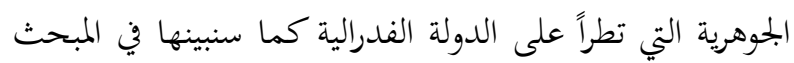

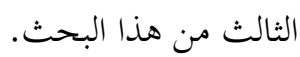


وفقاً لهذا النظرية يعد حقاً طبيعياً لا يجوز المساس به. وبالرغم من أن نظرية الحقوق الطبيعية هي نظرية صالحة لتفسير الأساس

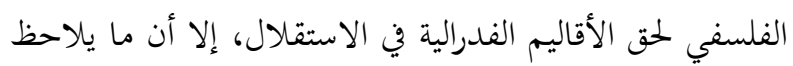
عليها أن هذه النظرية تفتح الباب على مصراعيه أمام إرادة الإقليم الفدرالي لممارسة حقه في الإستقلال متى ما يريد وكيفما

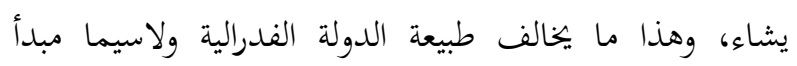
ديمومة الفدرالية.

\section{الفرع الثاني: نظرية العقد الاجتماعي}

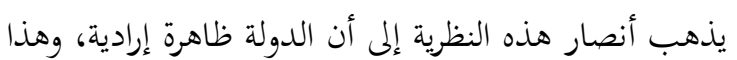

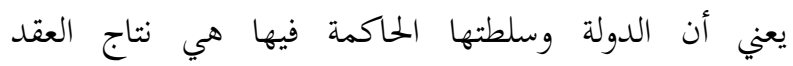
الإجتماعي (الاتفاق الاختياري الحر) بين أفراد الجماعة

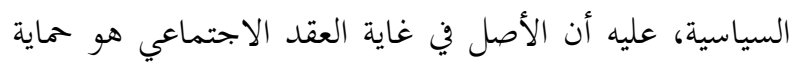

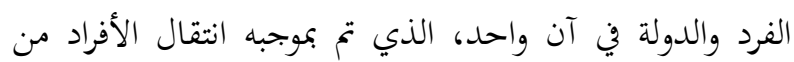
حالة الطبيعة إلى حالة المجتمع السياسي المنظم؛ ذلك نتيجة تنازل المواطنين عن كل أو بعض حقوقهم الطبيعية في مقابل استعادة حقوق وحريات جديدة تتفق والدولة (المختمع السياسي

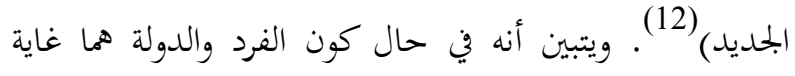
القانون فإن أساس التزام الدولة بإحترام الحقوق والحريات

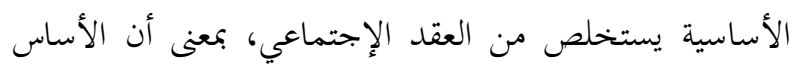
الفلسفي لحق الأقاليم الفدرالية في الاستقلال يتمثل في العقد الإسي الإجتماعي متمثلاً في دستور الدولة الفدرالية. ومن هذا المنطلق

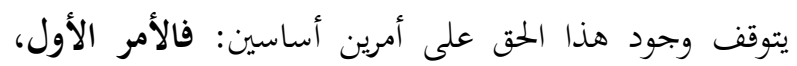
يتمثل في إرادة الأقاليم الفدرالية للأحتفاظ بحقها في الاستقلال

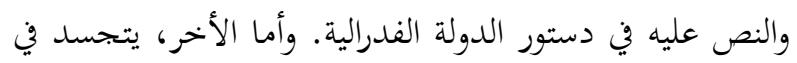
مدى إلتزام الحكومة الإتحادية بالدستوري الفدرالي، أي تلتزم الأقاليم الفدرالية بواجب الطاعة بتحاه الحكومة الإتحادية طلما أها بلها تعمل في حدودها التي رسمها الدستور الفدرالي كعقد إجتماعي الإي لئي سياسي. الفرع الثالث: نظرية التحديد الذاتي تحدف هذه النظرية إلى الربط بين سيادة الدولة وضرورة خضوعها للقانون، بما يستتبع بعد ذلك إيجاد أساس ملزم لها
يتمثل الأساس الفلسفي في بحموع الغايات النهائية للشيء،

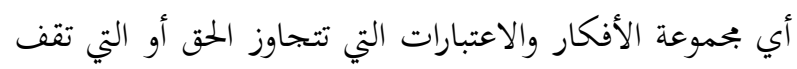
خلفه، وينظر إليها على أها سبب وجوده، والأساس الفلسفي

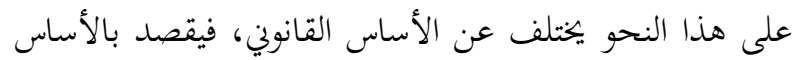
القانوين لحق ما، بحموعة المبادئ والقواعد القانونية التي يستند

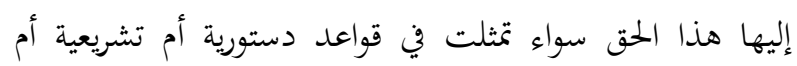
لائحية، بل تشمل أيضاً المبادئ التي استقر عليها القضاء

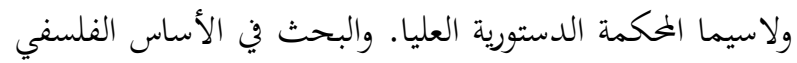
القانوين لحق الأقاليم الفدرالية في الاستقلال يتطلب تقسيم هذا

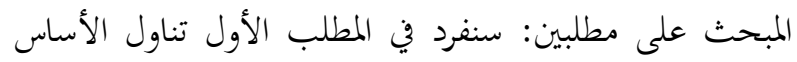

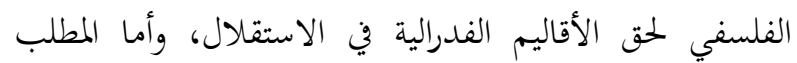
الثاني سنخصصه لدراسة الأساس القانوني لحق الأقاليم الفدرالية في الاستقلال، وذلك على النحو الآتي: المطلب الأول: الأساس الفلسفي لحق الأقاليم الفدرالية في

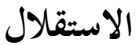
لقد اتفق الفقهاء والفلاسفة على وجوب إلتزام الدول

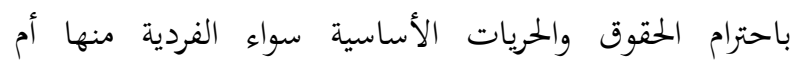
الجماعية، إلا أن الأساس الذي يقوم عليه هذا الالتزام كان محلاً

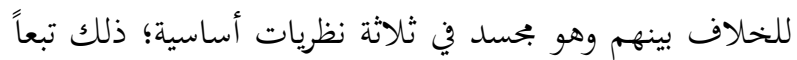

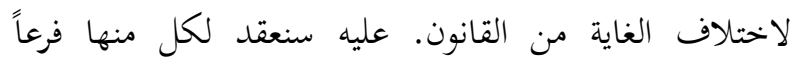
مستقلاً، فضلاً عن فرع مخصص لرآينا في هذا الشأن كما يلي:

\section{الفرع الأول: نظرية القانون الطبيعي} يذهب أنصار هذه النظرية إلى أن الدولة ومؤسساتها إن هي الهي الهي

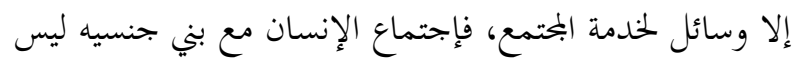

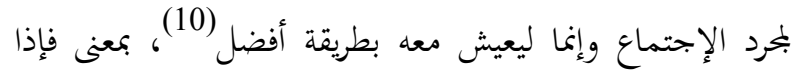
كانت الغاية من الدولة هي حماية حقوق وحريات الإنسان وبالتالي أها تشكل غاية القانون، فإن أساس التزام الدولة بإحترام حقوق الإنسان وحرياته الأساسية، يستخلص في القانون الطبيعي الذي يفترض أن الحق نشأ قبل الدولة والقانون، لذا فإِن إنهان وظيفة القانون هو حماية الحقوق والحريات لا إنشاءها(11). وتأسيساً على ذلك فإن حق الأقاليم الفدرالية في الاستقلال 
المجموعة الشمسية - يتجه إلى غايته بالطبيعة، وأما الموجود العاقل يتجه إلى غايته بالإدراك وبحرية الاختيار أي بالعقلانية.

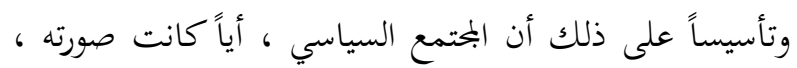

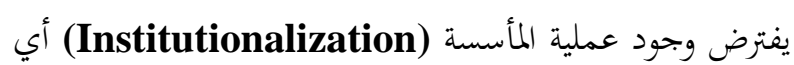
إيجاد بحموعة من الهياكل والقواعد المعيارية والقيمية بغية تحقيق

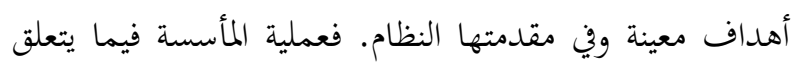
بممارسة الحقوق بصورة عامة قد تصطدم مع أصولها، ومن هنا

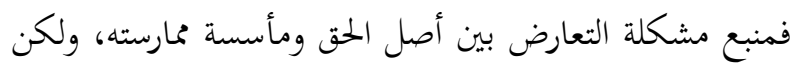

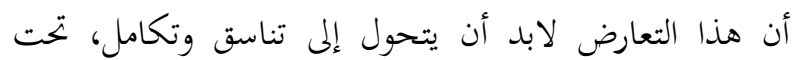



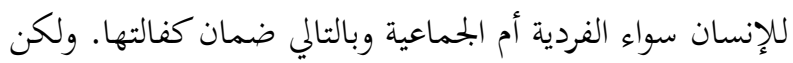

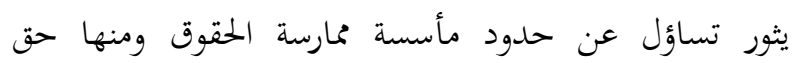
الأقاليم الفدرالية في الاستقلال، فالإجابة تقتضي بادئ ذي كئ بداء الإشارة إلى أن مسألة تأسيس ممارسة الحقوق والحريات الأساسية

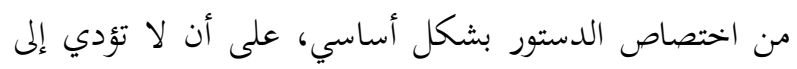

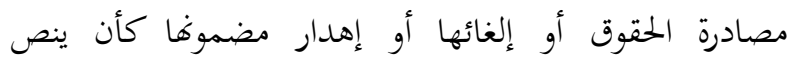
الدستور الفدرالي على منع حق الأقاليم الفدرالية في الاستقلال

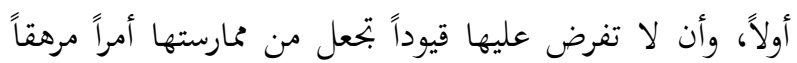
كأن يكون ممارسة حق الأقاليم الفدرالية في الاستقلال مشروطاً

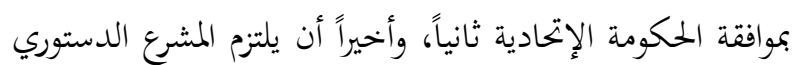
بمراعاة مبدأ التناسب والمنطقية حين التوازن بين الحقوق والمبادئ التي قد تتعارض فيما بينها؛ ومثال ذلك حق الأقاليم الفدرالية في الاستقلال ومبدأ ديمومة الفدرالية. إذن أن مسألة تأصل حق الأقاليم الفدرالية في الإستقلال وممارستها له تقتضينا الرجوع إلى طبيعة الدولة الإتحادية، فالفقه

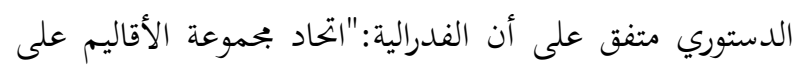
إنشاء تحالف مشترك "الدولة الاتحادية" مع بقاء هويتها الخاصة"، بكعنى أن الأصل في حق الأقاليم الفدرالية في

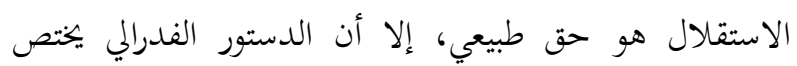
بمأسسة ممارسته ؛ ذلك بمقتضى فلسفة النظام الفدرالي ولا سيما فيما يتعلق بالتوازن الدستوري العمودي بين سلطة حكومات
بالحقوق والحريات الأساسية، وتقتضى أن الدولة برغم تمتعها

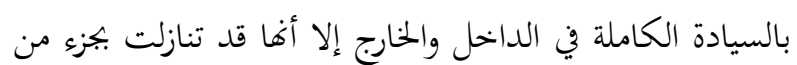
هذه السيادة يقابله الحقوق والحريات التي تمنحها للإنسان نزولاً

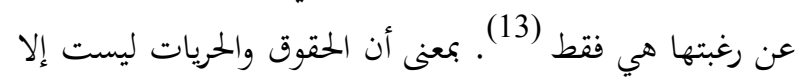
رخص تنحدر عن القواعد القانونية التي هي في الأصل أمر

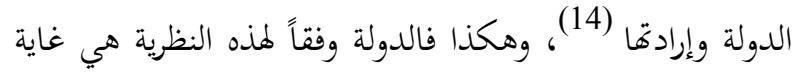

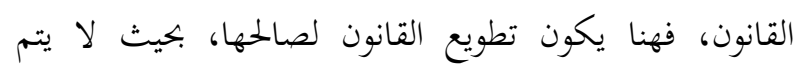
الاعتراف إلا بالحقوق والحريات الأساسية التي تتفق مع مصلحة الدولة، وبناء عليه فإن التزام الدولة بها يكون نابعاً من إرادهما ذاتما، أو ما يسمى بنظرية التحديد الذاتي. وعلى ذلك ذلك يمكن القول بإن موقف دستور الدولة الاتحادية من حق أقاليمها

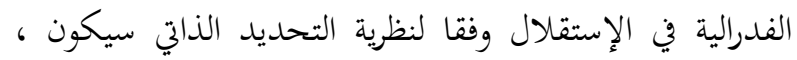

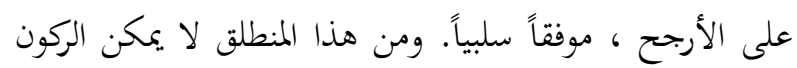

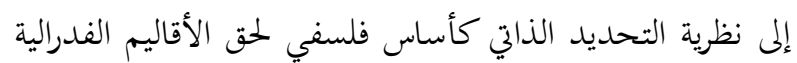

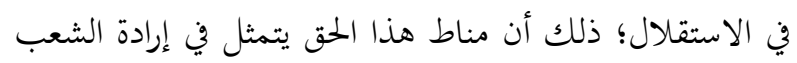

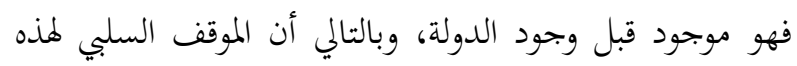
النظرية الذي لا ينسجم ومبدأ الإستقلال الذاتي للأقاليم

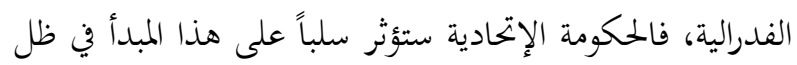
هذه النظرية؛ ذلك سواء تحت ستار ظاهرة الإمتناع التشريعي أم إمبل

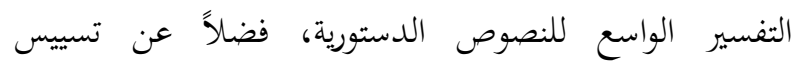
مؤسسات المراجعة القضائية الدستورية. الفرع الرابع: رأينا الخاص (نظرية التوازن)

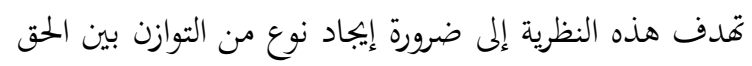

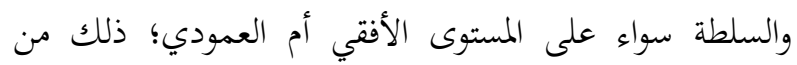
منطلق التميز بين وجود الحق بذاته من ناحية وبين كيفية ممارسته من ناحية أخرى، فالأصل في الحقوق أفا طبيعية ومنها

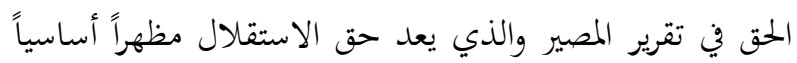

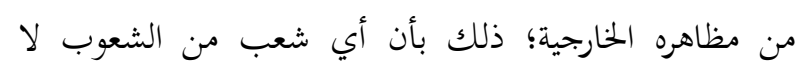

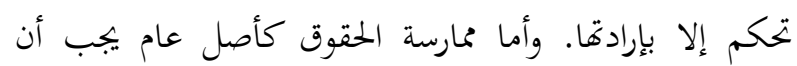
تكون مؤسساتياً، إذ أن لكل موجود ماهية ثابتة ونظاماً وميلاً

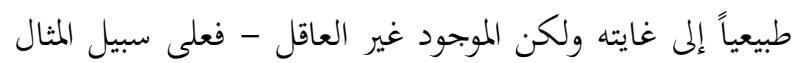


المشترك، وتعزيز الخير العام وتأمين نعم الحرية لنا ولأجيالنا القادمة، نرسم ونضع هذا الدستور للولايات المتحدة الأمريكية"(17). ومن هنا تثور أسئلة أخرى تتعلق بمسألة تبرير

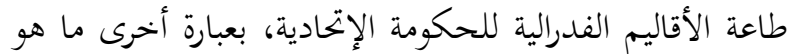

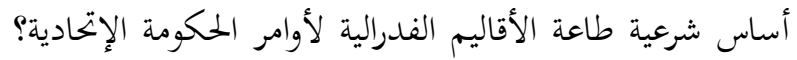

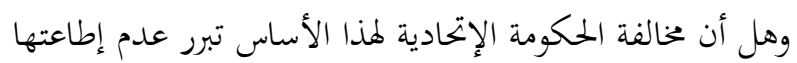

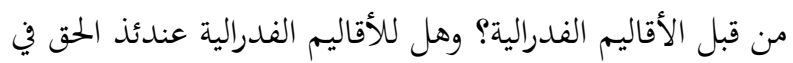
المطالبة بالاستقلال؟ حيث إن الإجتماع السياسي للأقاليم

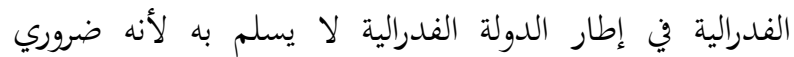

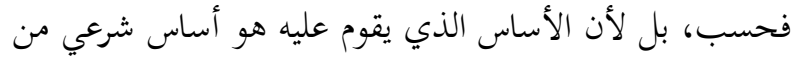

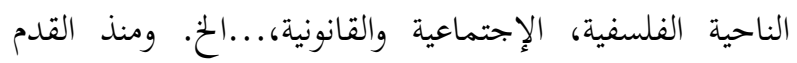

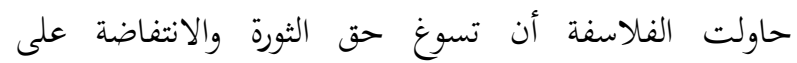
السلطات المستبدة، وبرروا حق اللجوء إلى الثورة، وفقاً للمفاهيم التقليدية، كوسيلة للوقوف ضد طغيان واستبداد السلطة (18)،

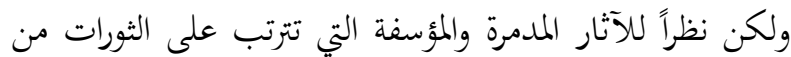

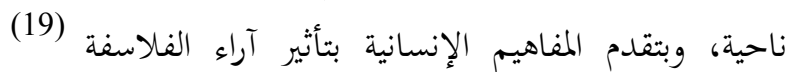

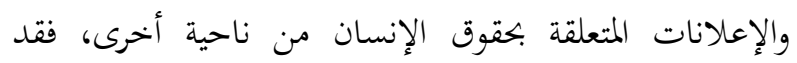

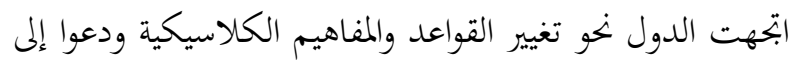
تنظيم البحتمع السياسي على أسس دستورية متطورة وسلمية ، ومن أهم تلك المتغيرات الجلذرية هو إقرار العديد من الدول

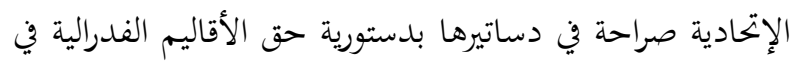
الاستقلال لإيجاد نوع من التوازن بين الصلاحيات الدستورية

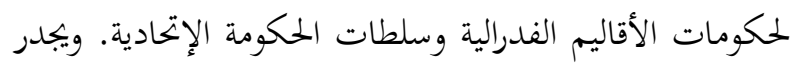
بنا الإشارة إلى أن موقف دساتير الدول الاتحادية يختلف فيما يتعلق بهذه المسألة: بعضها أعترفت رسمياً بصلاحية الأقاليم

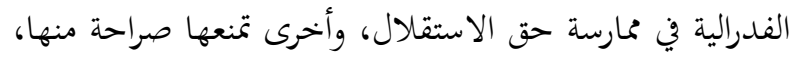
ولم تتناول بعضها مسألة الاستقلال بأي شكل من الإشكال، وفي حين بند نماذج فريدة منها تتناول مسألة الاستقلال ضمناً.

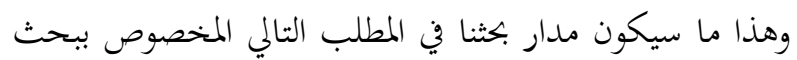
الأساس القانوني لحق الأقاليم الفدرالية في الاستقلال.
الأقاليم الفدرالية حماية لخصوصياتا وفقاً لمبدأ الإستقلال الذاتي من ناحية وتحقيق غاية الإتحاد بذاتا وفقاً لمبدأ ديمومة الفدرالية

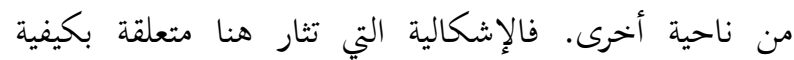
الحفاظ على التوازن الدستوري العمودي ولا سيما أن للفدرالية

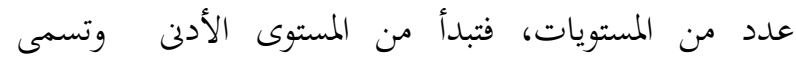

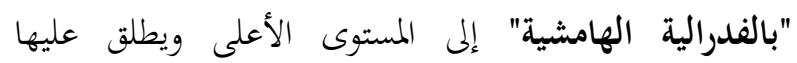

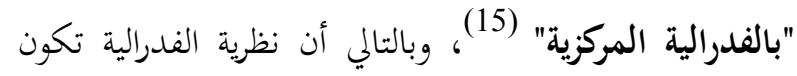

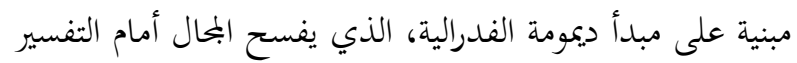
الواسع للاختصاصات الدستورية من قبل الحكومة الإتحادية

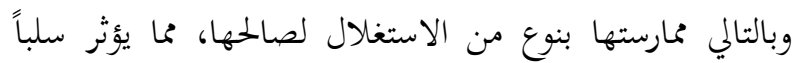
على مبدأ الاستقلال الذاتي للأقاليم الفدرالية. فالمنطق القانوني والفلسفي يقتضيان بأن يكون حل هذه الإشكالية عن طريق مؤسسات المراجعة القضائية الدستورية، غير أن ظاهرة الإمتناع

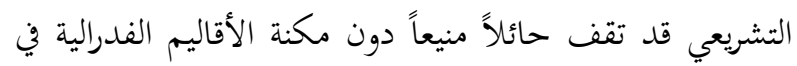
اللجوء إلى هذه المؤسسات، فضلاً عن مسألة تسييسها أحياناً

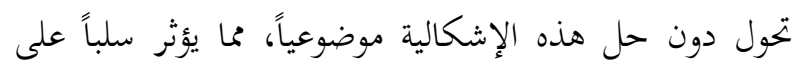
فعالية نصوص الدستور المنظمة للحقوق الأقاليم الفدرالية وخاصة تلك التي لا يمكن تطبيقها دون تدخل تشريعي.

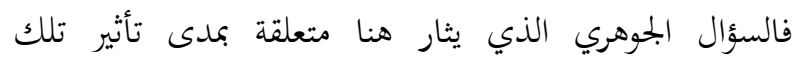
النصوص الدستورية في رضا الأقاليم الفدرالية بالدستور الفدرالي

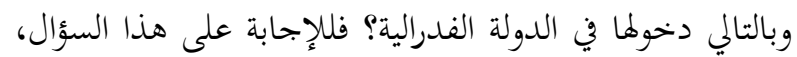
بادئ ذي بدء نشير إلى أن إجتماع الأقاليم الفدرالية في إطار

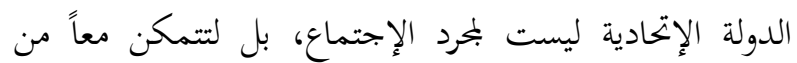
النهوض والتقدم والتنمية بطريقة أفضل. فالحكومة ، سواء منها لإلمان الموحدة أم الاتحادية ، ضرورية إلا أن مبرر وجودها، بل وبقائها

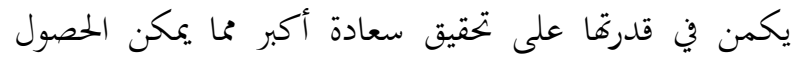

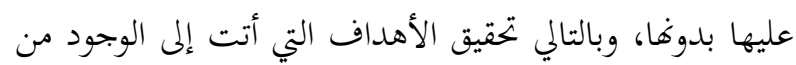

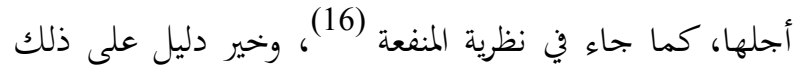

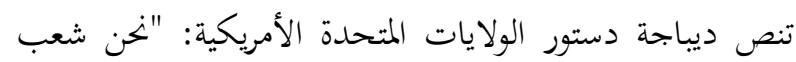

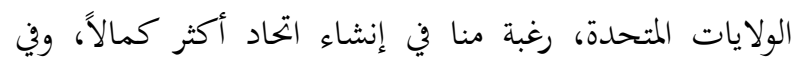
إقامة العدالة، وضمان الاستقرار الداخلي، وتوفير سبل الدفاع 
في عجزها: "... وهذا الدستور ضامن لوحدة العراق". فالمفهوم المخحالف سواء لتلك الفقرة من ديباجة الدستور أم هذا العجز

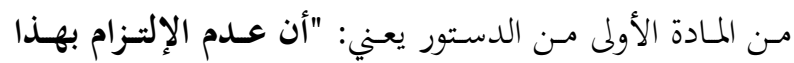

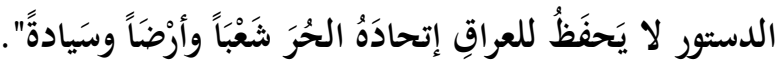
الفرع الثاني: الدساتير السلبية

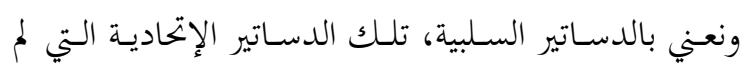

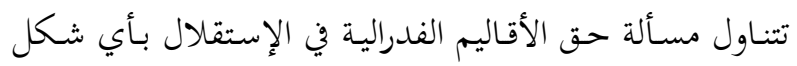
من الإشكال، أو تمنعها صراحة منه. ومثال الدساتير الإتحادية التي لم تتناول مسألة الاستقلال بأي شكل من الإشكال دستور

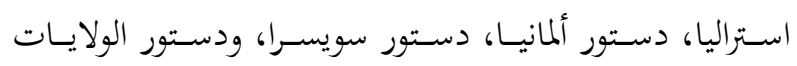

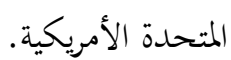

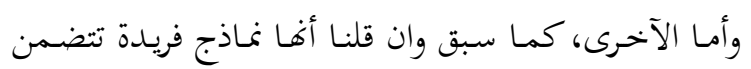
نصوصاً تمنع صراحة الأقاليم الفدرالية المكونة للدولة الإتحادية

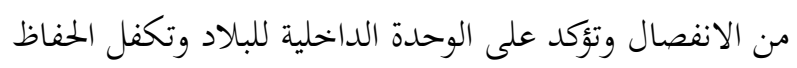

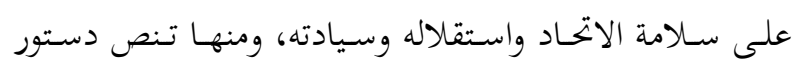

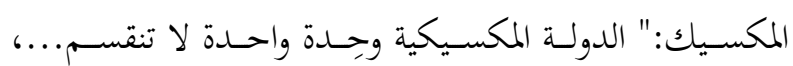

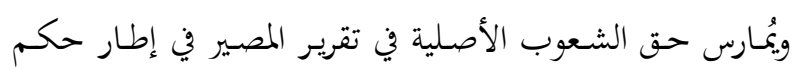

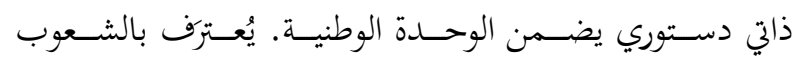
والبحتمعات الأصلية في دساتير وقوانين الكيانات الاتحادية والتي

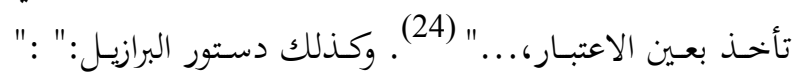

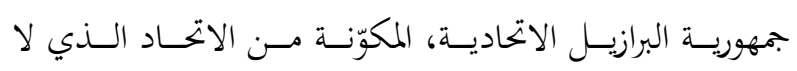

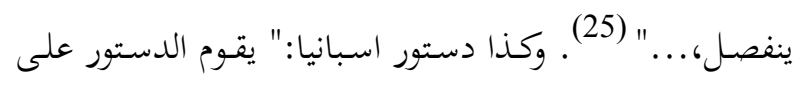

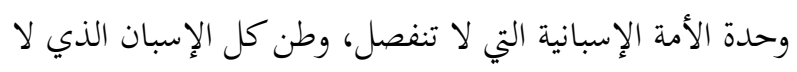

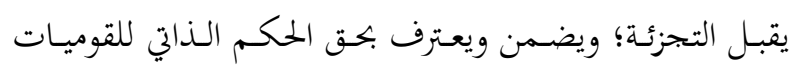
والمناطق التي يتكون منها ويضمن ويعترف بالتضامن فيما بينه"

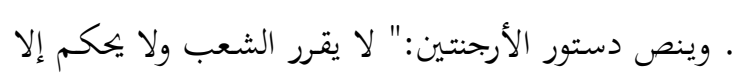

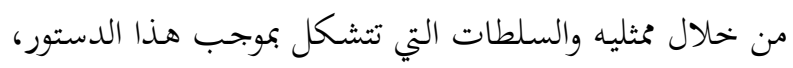

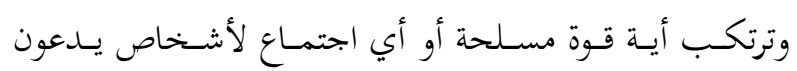

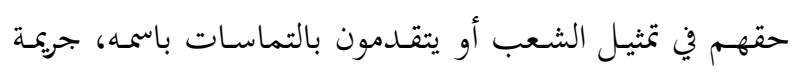

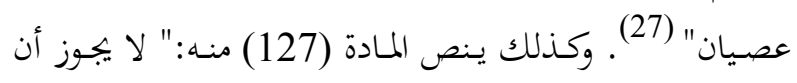

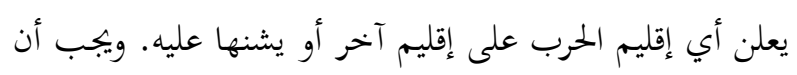

المطلب الثاني: الأساس القانوني لحق الأقاليم الفدرالية في الاستقلال

يقصد بالأساس القانوني بجموع المبادئ والقواعد القانونية التي يستند عليها الإقليم الفدرالي في ممارسة حقه في الاستقلال

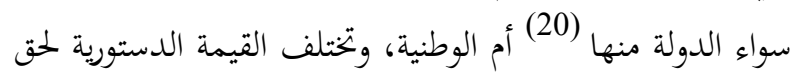
الأقاليم الفدرالية في الاستقلال من دستور إتحادي لآخر، فوفقاً التهاء لهذه الحيثية يمكنا تصنيف الدساتير الإتحادية: الفرع الأول: الدساتير الإيجابية ونعني بالدساتير الإيجابية، تلك الدساتير التي تعترف صراحة الإليهة

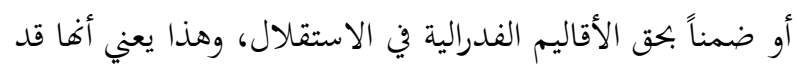

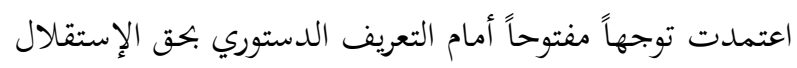
للأقاليم، ورسم مساره الشرعي بغية تجنب الأزمات الدستورية. ومثـال الدسـاتير الإتحاديـة التي تعـترف صـراحة بحـق الأقـاليم الفدرالية في الاستقلال: دستور الاتحاد السوفيتي للأعوام 1924 1936 و1977 حيث أها تتضمن نصوصا بحيز حق الإستقلال للجمهوريـات الاتحاديـة، فالمـادة (72) مـن الدسـتور الأخسير:"

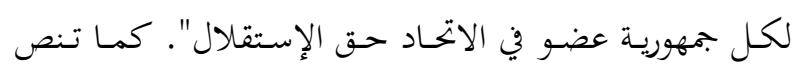

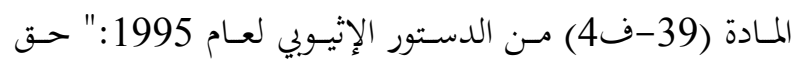

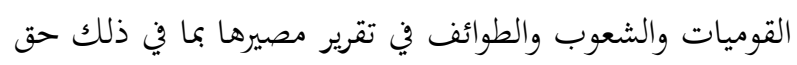

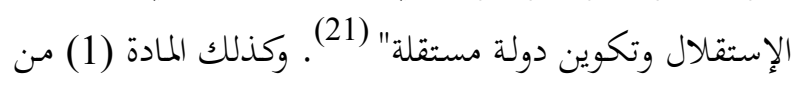

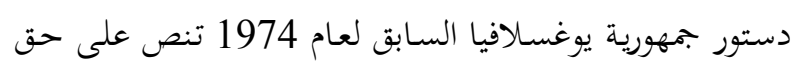
الاستقلال (22) . ونصت المادة (113) من دستور اتحاد سانت كيستس ونفـيس لعـام 1983 وضـعت وصـفا مفصـلا لمســار

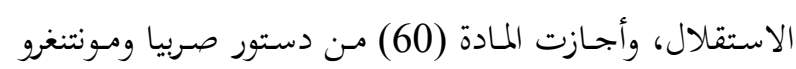

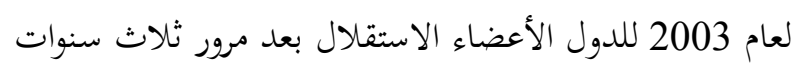
من وضعه، وكذلك الفقرة (2) مـن المادة (222) من الدستور

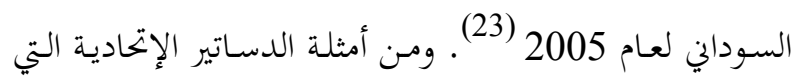

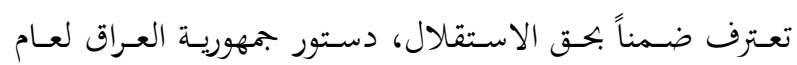

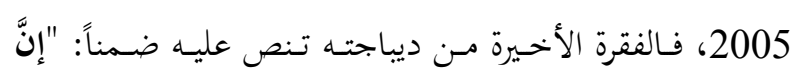

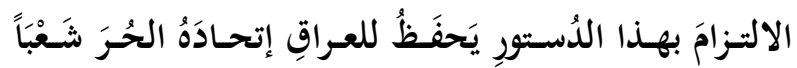

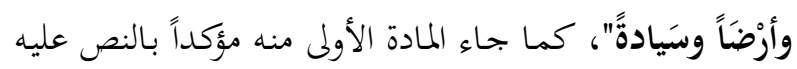


تحرم أية ولاية وبدون موافقتها من حقها في التصويت المتساوي

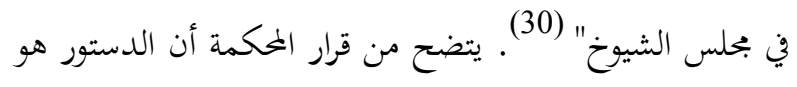

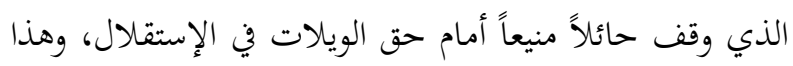
يعني أن صلاحية ممارسة حق الإستقلال تختلف بإختلاف موقف الدستور، فالبنسبة للدساتير الإتحادية الإيجابية التي تعترف الإنفائ

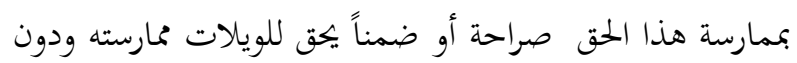

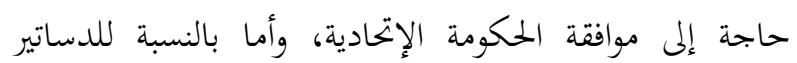
الإتحادية السلبية فإن ممارسة حق الإستقلال يكون موقوفاً على الإسلى إرادة تعديل الدستور من ناحية ومدى إلتزامها بالدستور ولاسيما

$$
\text { منه النصوص الأساسية. }
$$

الفرع الثاني: المحكمة الدستورية ليوغسلافيا السابق الاسئ

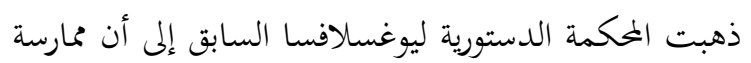
حق تقرير المصير والانفصال المنصوص عليه في الدستور من صلاحية الشعب اليوغسلافي. وهذه المحكمة كانت في الأصل

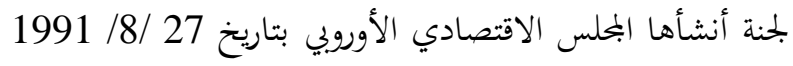
وتعرف هذه اللجنة باسم للحنة بادنتر"Badente " لتقديم

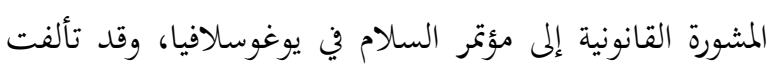
من رئيس وخمسة أعضاء من رؤساء المحاكم الدستورية في دول

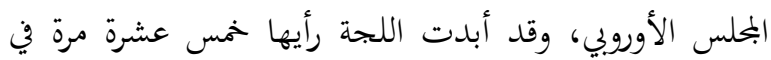

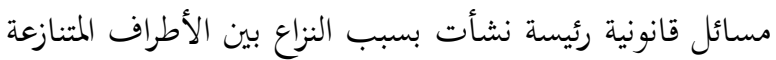
في جمهوريات يوغسلافيا السابقة، وقد ورد تعليقها المشار إليه أعلاه في رأيها الثاني حرفياً (31). الفرع الثالث: المحكمة العليا الكندية

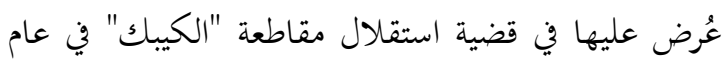

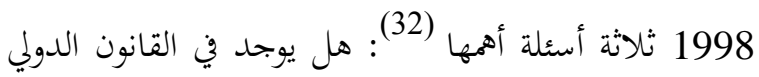
حق تقرير مصير يعطي سكان "الكيبك" حقاً الاستقلال

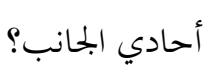
أكدت المحكمة أن القانون الدولي لا يمنح الأجزاء المكونة

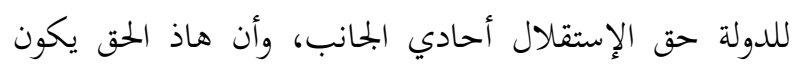

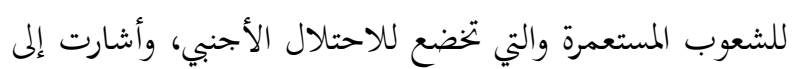

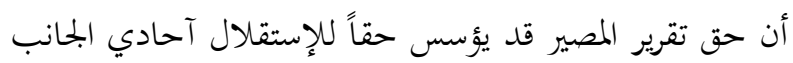

تقدم شكاوى الأقاليم إلى محكمة العدل العليا، التي تفصل فيها.

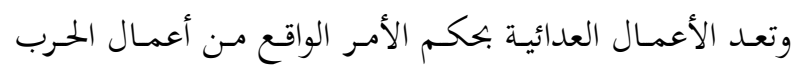

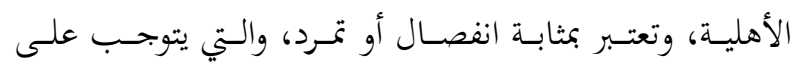
الحكومة الاتحادية قمعها والمعاقبة عليها طبقاً للقانون" (28).

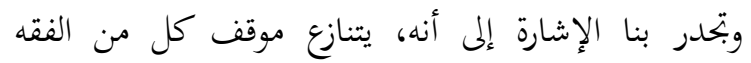

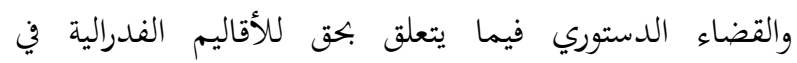

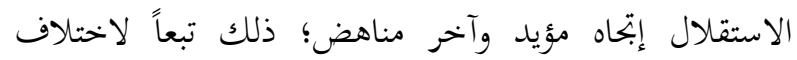

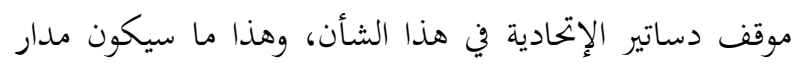

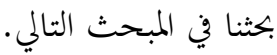

المبحث الثاني: موقف الفقه والقضاء الدستوري من حق الإقاليم الفدرالية في الاستقلال

يتنازع الفقه والقضاء الدستوري فيما يتعلق بحق الأقاليم الفدرالية في الاستقلال ابتحاه مؤيد وآخر مناهض، سنتعرض ذلك في مطلبين مستقليين، وعلى النحو الأتي: المطلب الأول: موقف القضاء الدستوري سبق لنا القول بأن البحث يقتصر على القضاء الدستوري

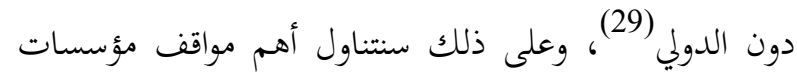
المراجعة القضائية الدستورية في هذا الشأن كما يأتي: الفرع الأول: المحكمة العليا الأمريكية أصدرت قرارها الحاسم عام (1868) في هذا البحال بأنه

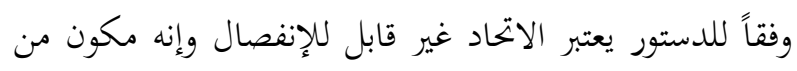
ولايات غير قابلة للإنفصال، وإن الطريق الوحيد الذي تستطيع الولايات أن تنفصل به أو تستطيع الاتحاد أن يفصل أحد

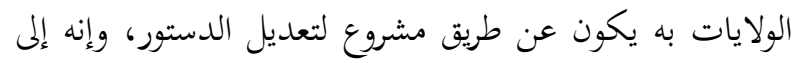

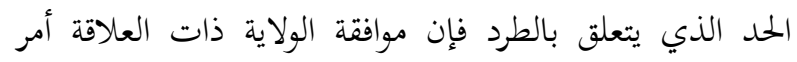

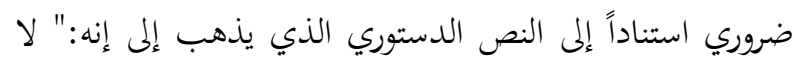


تنص على إنه:" نحن شعب الولايات المتحدة نقر وننشأ هذا

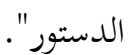

الفرع الثاني: الأتجاه المؤيد لحق الأقاليم الفدرالية في

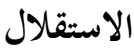

يكاد يكون الإجماع منعقداً بين أنصار هذا الاتحاه فيما

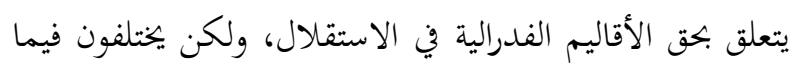

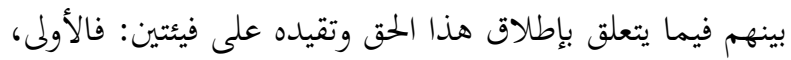

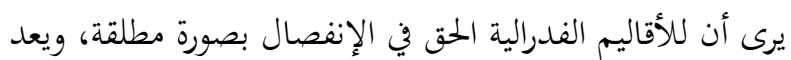

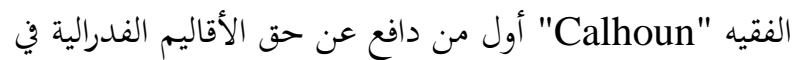

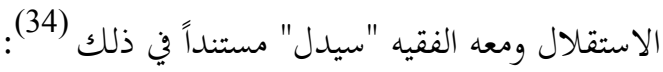
1. إن الفدرالية هو اتفاق بين دول مستقلة.

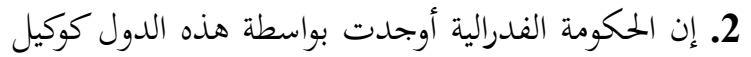
لما لتنفيذ أحكام هذا الاتفاق المدرجة في الدستور الفدرالي. 3. إن كل دولة لها الحق في أن تقرر لنفسها ما إذا كان

عملا من أعمال الحكومة الفدرالية خروجاً من أختصاصاتها. وكذلك يرى (شارل ديوراند) أن الدولة الفدرالية هي صورة

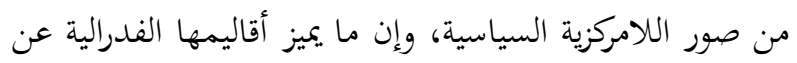
المحافظات والكميونات القائمة في ظل اللامركزية الإدارية هو

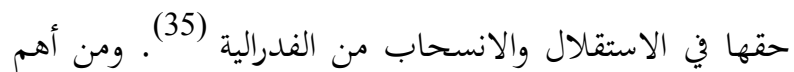
المآخذ على هذا ، نظرية كالهون وسيدل، بأن هذه النظرية واجهت الفرض الخاص بتكوين الفدرالية عن طريق الاندماج بين دول مستقلة عن بعضها وذات سيادة، قائلاً باستمرار سيادة

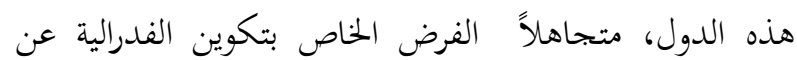

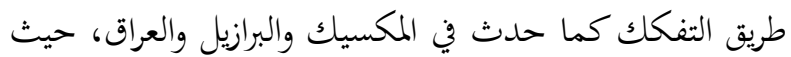
أعلنت بأن الأمة هي التي تبنت نظام الفدرالي الدستوري (36). وأما الفيئة الأخرى: يرى - وعلى رأسهم الفقيه "Wheare"

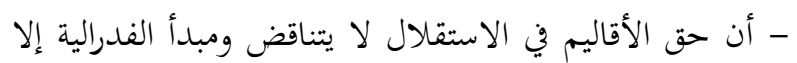

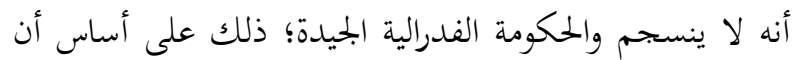

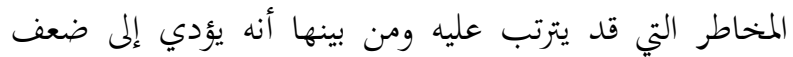

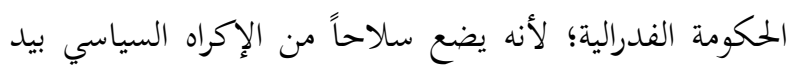
حكومات الأقاليم التي قد تستعمله للحصول على أهدافها.
في ظرف خحاصة مؤداها:" أنه عندما يحال بين شعب ما وحقه

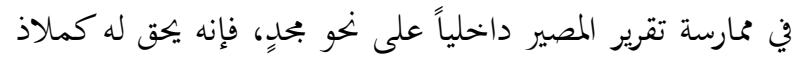

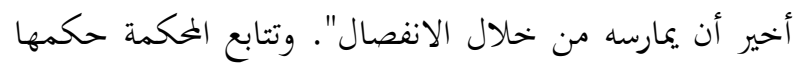
بالقول في حيثيات الحكم إنَّه:" وفي جميع الحالات السابقة يتمتع الشعب المعني بحق تقرير المصير الخارجي لأنَّه قد منع من

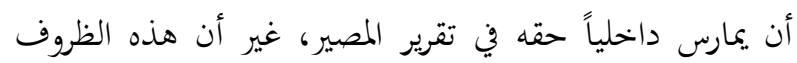
الاستثنائية لا تنطبق على الوضع في كيبك". المطلب الثاني: موقف الفقه من حق الأقاليم الفدرالية في الاستقلال

كانت مسألة حق الأقاليم الفدرالية في الاستقلال ولا تزال

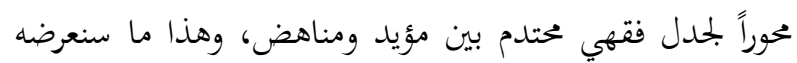
خلال فرعين وعلى النحو الأتي:

الفرع الأول: الأتجاه المناهض لحق الأقاليم الفدرالية في الاستقلال يرى أصحاب هذا الاتحاه أن الفدرالية يكون نظاماً أبدياً

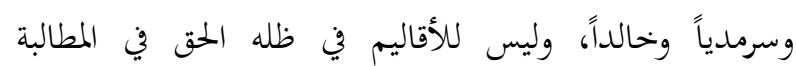
بالانفصال، مستندين في ذلك على بعض البراهين والأسانيد القانونية، ومن أهمها (33): 1. إن الدولة الفدرالية تقوم على مبدأ ديمومة الفدرالية الذي الذيائيل يحول بينها وبين أقاليمها الفدرالية الحق في الاستقلال.

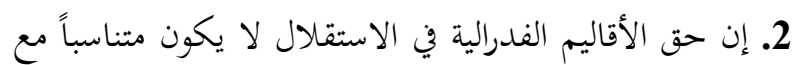

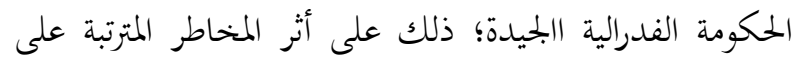

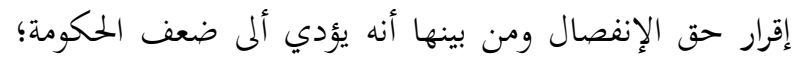
ذلك لأنه يضع سلاح من الإكراه بيد الأقاليم الفدرالية التي قد لد إلى تستعمله للحصول على أهدافها.

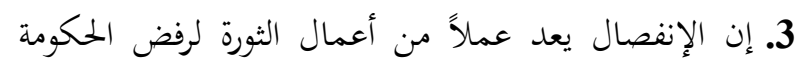
القائمة ولإيقاف الدستور السياسي عن العمل عن طريق الثورة.

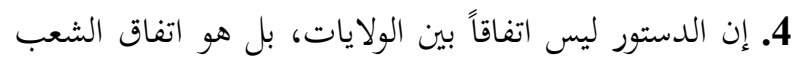
نفسه مستندين في ذلك على مقدمة الدستور الأمريكي التي 
بالقوانين التي تم تشريعها في إقليم كوردستان منذ 1992، وتُعُد القرارات المتخذة من حكومة إقليم كوردستان. بما فيها قرارات المحاكم والعقود. نافذة المفعول، ما لم يتم تعديلها أو إلغاؤها حسب قوانين إقليم كوردستان، من قبل الجهة المختصة فيها، وما لم تكن مخالفة لهذا الدستور).

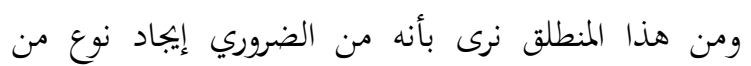
التوازن والإنسجام بين مبدأ ديمومة الفدرالية وحق الأقاليم

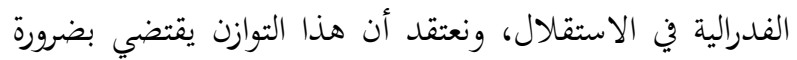
تنظيم شروط ممارسة حق الأقاليم الفدرالية في الاستقلال في الدستوري الفدرالي على نهو عدم استغلال مبدأ الديمومة

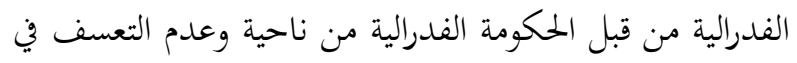

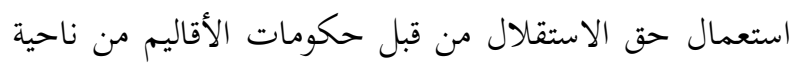

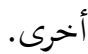

\section{المبحث الثالث: إقليم كوردستان - أن أن جمهورية العراق أنموذجاً}

يتطلب البحث في مدى صلاحية إقليم كوردستان -

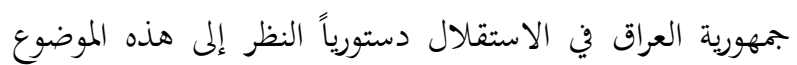
من منظورين: فالأول منهما، يتمثل في بيان الوضع القانوين

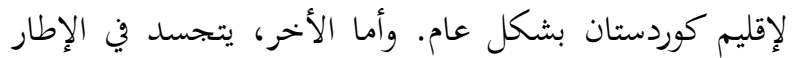

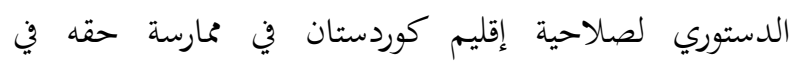
الاستقلال. ويكون ذلك من خلال مطلبين مستقلين وعلى النحو الأتي: - الآن

المطلب الأول: الوضع القانوني العام لإقليم كوردستان

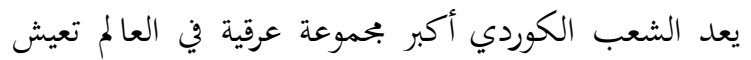
دون دولة خاصة بها، ويذهب معظم المؤرخين إلى أن القضية الكوردية، في العصر الحديث، بدأت في الظهور على مسرح

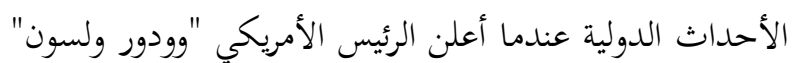

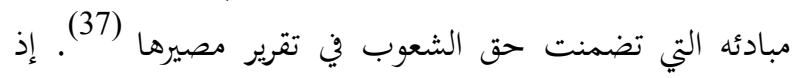
عقدت الدولة العثمانية ، بعد هزيمتها في الحرب العالمية الأولى،

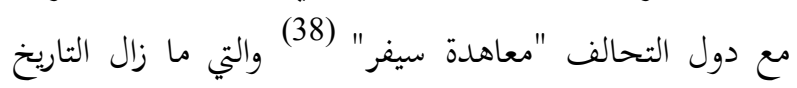

ونحن بدورنا نؤيد حق الأقاليم الفدرالية في الاستقلال بضوابط وشروط: وإن كان الأصل في الدولة الفدرالية هو تأسيسها على مبدأ ديمومة الفدرالية، فإن المحافظة على التوازن الدستوري العمودي بين سلطة حكومات الأقاليم الفدرالية وسلطة الحكومة الفدرالية يقتضي في مقابل ذلك بضرورة الاعتراف بحق الأقاليم الفدرالية في الاستقلال، ونستند في ذلك:

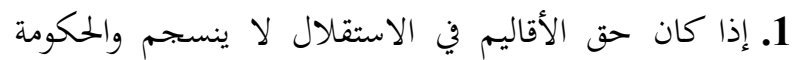

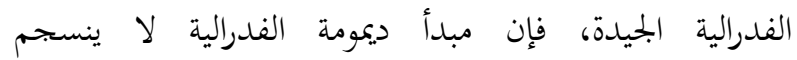
والحكومات الجيدة للأقاليم الفدرالية؛ عديدةٌ هي المخحاطر المترتبة عليه، ومن بينها أنه يؤدي إلى ضعف حكومات الفيدات الأقاليم مما

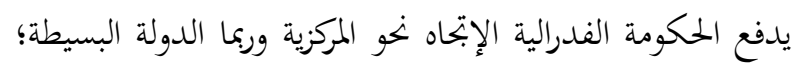
لأنه يضع سلاحاً من الإكراه بيد الحلكومة الفدرالية التي قد الدهاه تستعمله للحصول على أهدافها.

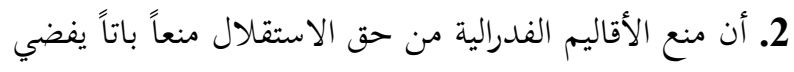
إلى سوء استغلال الاختصاصات الحصرية للحكومة الفدرالية

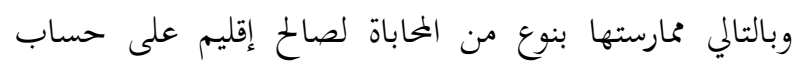
إقليم أخر. 3. أن مبدأ ديمومة الفدرالية يفضي إلى الإخلال بالتوازن الدستوري العمودي؛ ذلك لأنه يفسح المحال أمام إشكالية

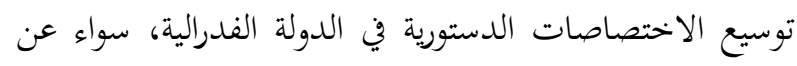

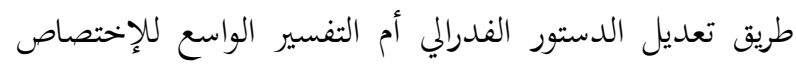

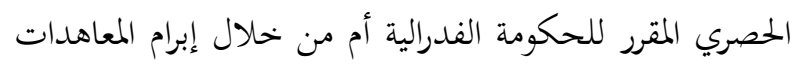
الدولية في محال اختصاصات حكومات الأقاليم.

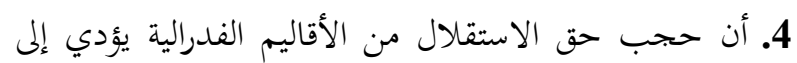
تقوية مركز القادة الفدرالية على حساب القادة الأقليمية. 5. إن الدستور يكون اتفاقاً بين شعوب الولايات، ومثال قرار برلمان إقليم كوردستان رقم (22) في 1992/10/4 الخاص بإعلان الفدرالية نيابة عن شعب إقليم كوردستان، وجاءت المادة

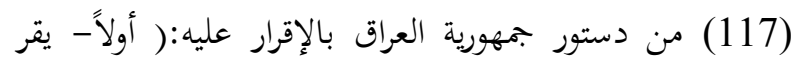
هذا الدستور، عند نفاذه، إقليم كوردستان وسلطاته القائمة إقليماً فيدرالياً). وكذلك المادة (141) منه:( يستمر العمل المليم 
الشعب الكوردي وطمس معالم حقهم في تقرير مصيرهم كحق مكفول لكل شعب بموجب المواثيق الدولية. وارتكب النظام

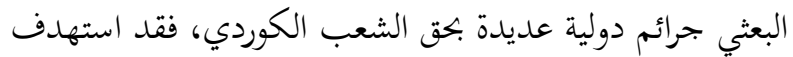
النظام البعثي الكورد كجماعة إثنية تشكل جزاً من القومية الكوردية، والجماعة الاثنية هي من ضمن الجماعات المذكورة في اتفاقية عام 1948 لمنع جريمة الإبادة الجماعية، و المعاقبة عليها

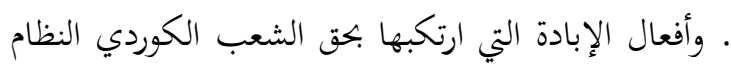
السابق شملت نوعي الإبادة: الإبادة المادية والإبادة المعنوية فالإبادة المادية (الاستئصال المادي) تحقق من خلال ارتكاب

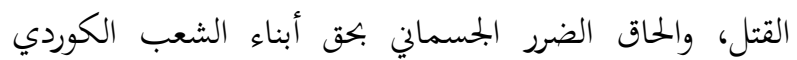

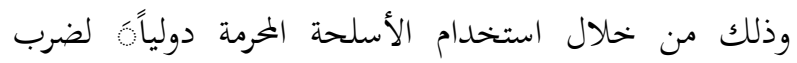
المناطق الكوردية ولاسيما إلقاء القبض على أكثر من ثمانية آلاف بريء من البارزانين في سنة 1983 ودفنهم في قبور جماعية، واستخدام الأسلحة الكيماوية في حملات الأنفال لعام

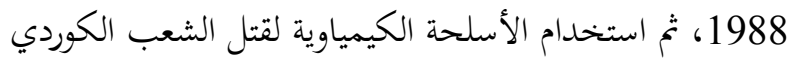
في قضاء حلبجة في 1988/3/16 (45) وتدمير أكثر من " 4500 " قرية تمثل ما يزيد 90\% قديجة في من ريف كوردستان (46).

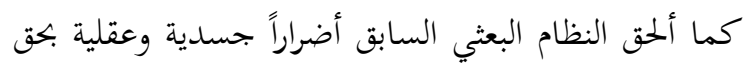
أبناء العشب الكوردي من خلال تعذيبهم للحصول على

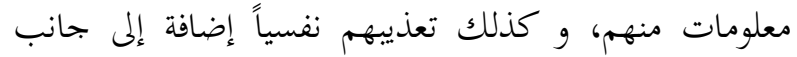
التعذيب الجسدي من خلال التخويف و الترغيب لقاء الحصول على معلومات منهم من خلال تمديدهم بإلحاق الضرر بعوائلهم

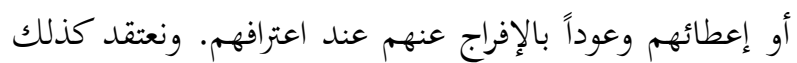

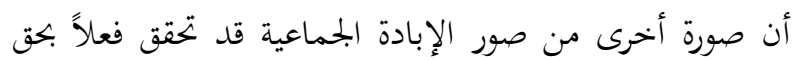
أبناء الشعب الكوردي وهي صورة منع إبحاب الأطفال، أو منع التناسل و ذلك من خلال قيام النظام البعثي السابق عام

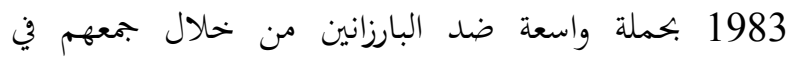
معسكرات خاصة، وفصل الرجال عن النساء مما أدى بالنتيجة

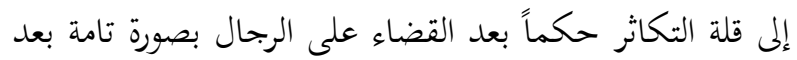

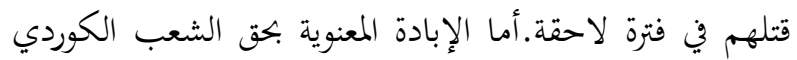
من خلال التأثير في النفس البشرية الكوردية بنية تصفيتهم كلياً
الكوردي ينظر إليها باحترام حيث كانت أول تدويل للقضية

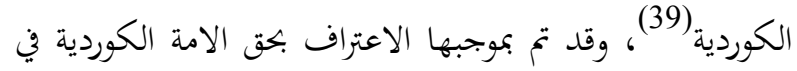
حكم ذاتي يتحول خلال سنة إلى استقلال تام لدولة كوردية تضم معظم كوردستان بضمنها كوردستان الجنوبية التي عرفت فيما بعد ، بعد تأسيس الدولة العراقية ، بـ" كوردستان العراق". ولكن مع بنحاح الحركة القومية التركية وما أعقبها من استبدال

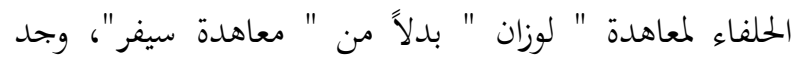
الكورد أنفسهم مقسمين بين خمس دول هي : " تركيا وإيران

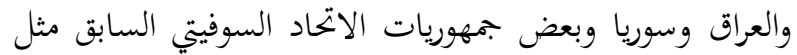

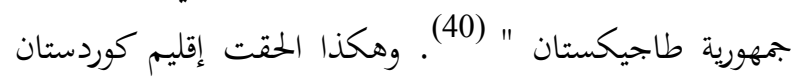
العراق (ولاية الموصل) قسراً وبالضد من إرادة سكاها بالدولة

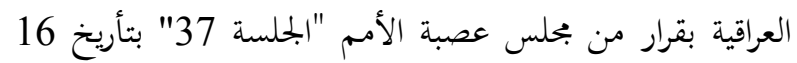
كانون الأول 1925، رغم احتجاجات وثورات هذه الامة ورغم

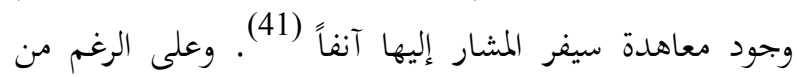
تعدد القيادات السياسية الحاكمة التي مرت في تاريخ العراق الحديث، فإها فشلت في تحقيق تسوية سياسية وقانونية تحقق التعايش بين الكورد والعرب واندماجهما في إطار الوحدة الوطنية

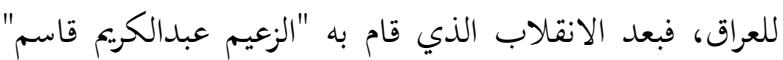
في 14 تموز 1958 اعترف الدستور العراقي المؤقت لعام 1958 بالحقوق القومية للعشب الكوردي بالنص:"... ويعتبر العرب المراب والكورد شركاء في الوطن العراقي ويقر هذا الدستور حقوقهم

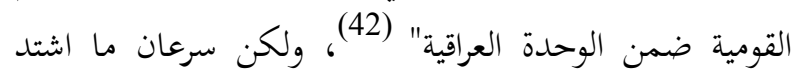

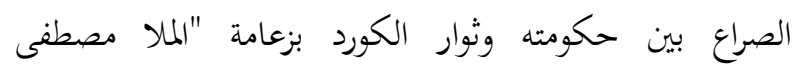

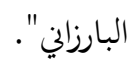
وعندما تسلم حزب البعث مقاليد السلطة وجهت الحكومة نداء إلى زعيم الكورد للدخول في مفاوضات اصطدمت بإصرار

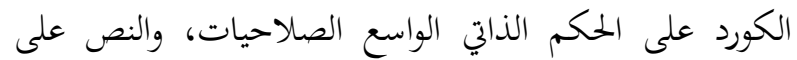

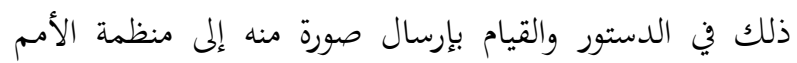
المتحدة، وفي بيان "11 آذار 1970" استجابت الحكومة لهذا لئاس المطلب (43). ولكن على الرغم من ذلك قامت الحلكومة العراقية بتوقيع اتفاقية، وانتهج نظام البعثي البائد سياسة القمع ضد أبناء 
كوردستان أدت إلى تحرر المدن الرئيسية ومايتبعها من وحدات

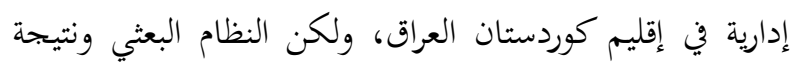
لطبيعته الدكتاتورية حاول قمع الانتفافضة من خلال الوسائل

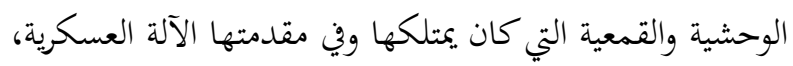

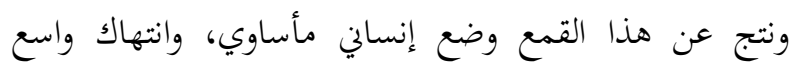

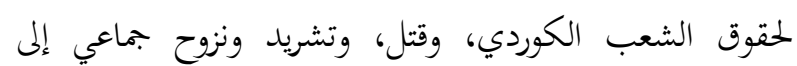

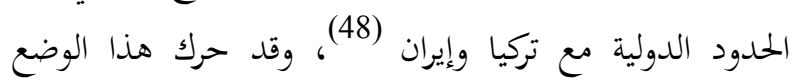
المأساوي وما تناقله الرأي العام العالمي من خلال مختلف وائل وسائل

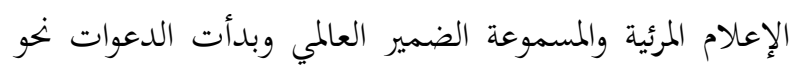

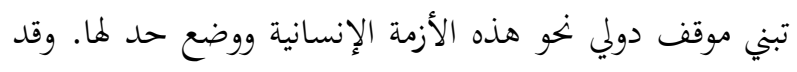

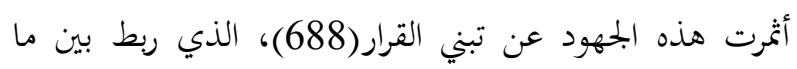

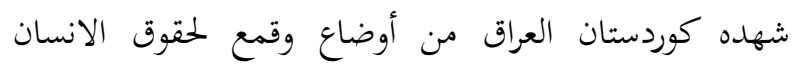

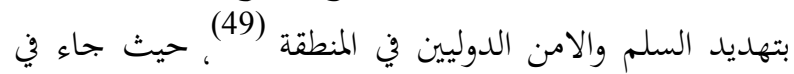
ديباجة القرار( أن بحلس الامن...، واذ يساوره القلق الشديد ازاء القمع الذي يتعرض له السكان المدنيون العراقيون في أجراء كثيرة من العراق، والذي شمل مؤخرا المناطق السكانية الكوردية في العراق وأدى الى تدفق اللاجئين على نطاق واسع عبر الحدود ولدي الدولية والى حدوث غارات عبر الحدود بما يهلدد السلم والامن الدوليين في المنطقة: 1. يدين القمع الذي يتعرض له السكان المكان المدنيون العراقيون في اجزاء كثيرة من العراق والذي شثمل مؤخرا المناطق السكنية الكوردية، وتمدد نتائجه السلم والامن الدوليين في المنطقة. كما أكد القرار على ضرورة ايصال المساعدات

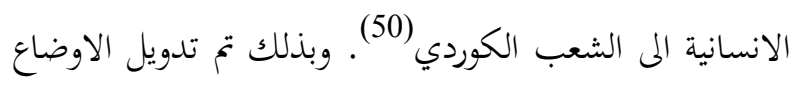

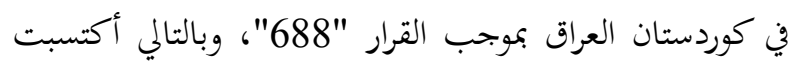

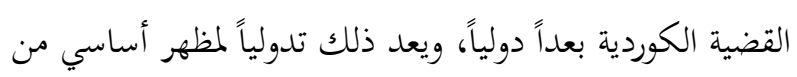

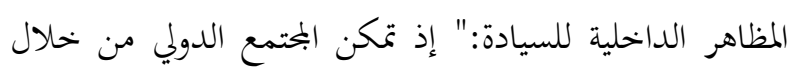
دول التحالف ولأول مرة في تاريخه من اقتطاع أجزاء من اقليم

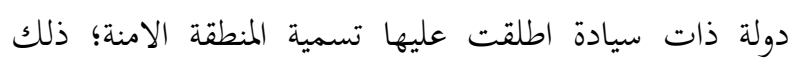

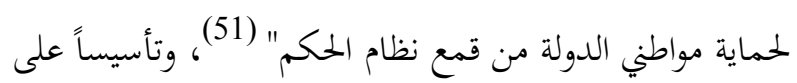

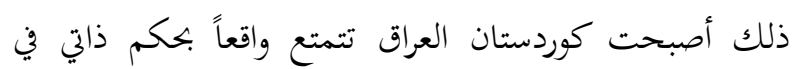

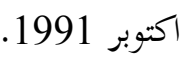

أو جزئياً وهذا ما يسمى الاستئصال المعنوي فأن النظام البعثي الأفعال المكونة لهذا النوع من الإبادة من خلال إخضاع الخاع أبناء

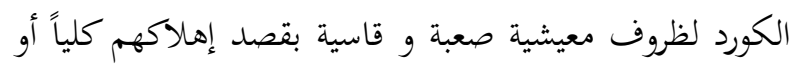

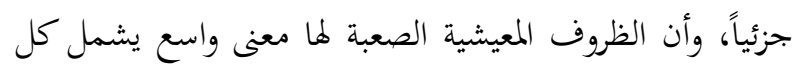

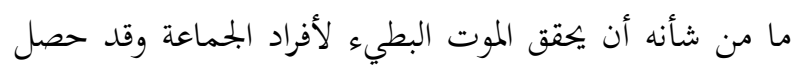

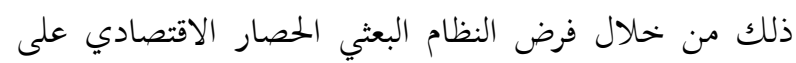

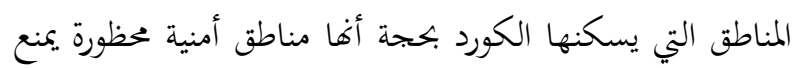

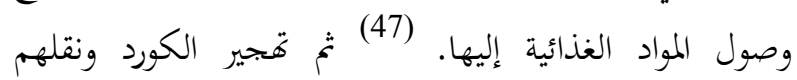

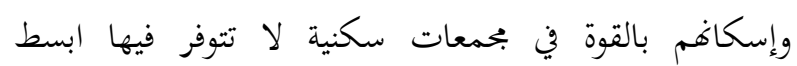
متطلبات الحياة المعيشية التي تتناسب مع الكرامة الإنسانية، فضلا عن الابادةالثقافية و السياسية و التي تعني ارتكاب

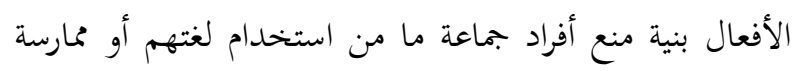

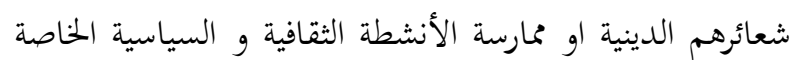

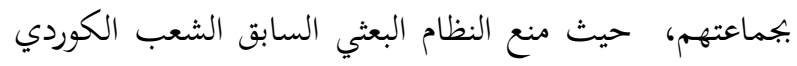
من حق ممارسة الثقافة الخاصة بهم و التعبير عنها و عن تراثهم و تأريخهُم. و ولفترة طويلة من الزمن وبحكم تصارع المصالح الدولية في فترة الحرب الباردة تعرضت القضية الكوردية الى ومآسي

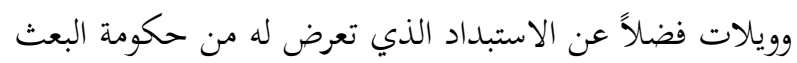

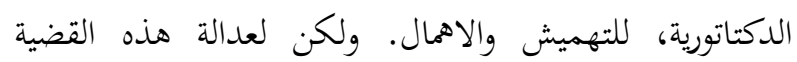
واصرار الشعب الكوردي في الوصول إلى حقه المشروع في تقرير مصيره مهما كانت التضحيات بقيت هذه القضية حية ولم تمت،

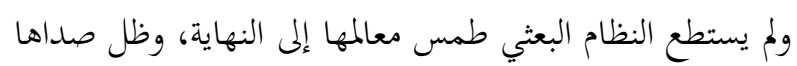
يدوي في نفوس كل الأحرار في العالم ومناصري حقوق الإنسان والحرية. وشاءت الظروف أن تلقى هذه القضية آذاناً صاغية في

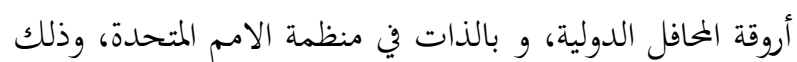

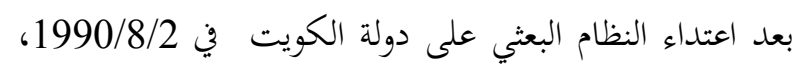

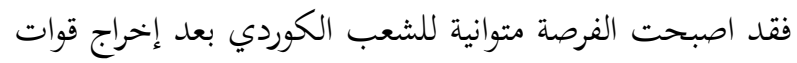

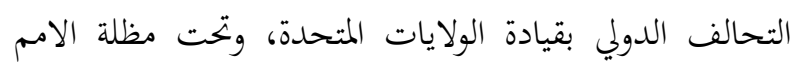
المتحدة قوات هذا النظام المعتدي، لإعلان حقه في تقرير مصيره والتخلص من النظام الدكتاتوري، فقد عمت في بداية شهر آذار من عام 1991 انتفاضة شعبية عارمة في مدن وقصبات 
اجتاحت الاتحاد السوفتي في أوائل التسعينات من من القرن المنصرم من خلال استقلال أرمينيا وأذربيجان واوزبكستان الانسان

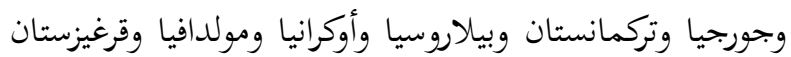
وطاجيكستان وكازاخستان عنه. وأما الثانية، حالة تغيير الظروف الخاصة بأقليم من الأقاليم الفدرالية كأن يصل الإقليم إلى مستوى معين من التطور سياسياً

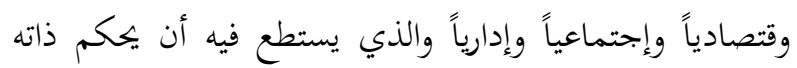

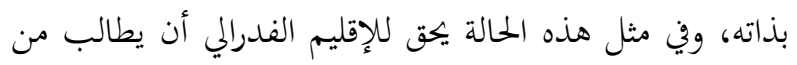

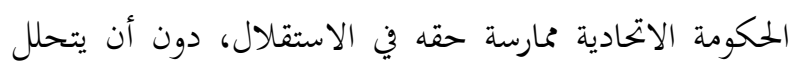

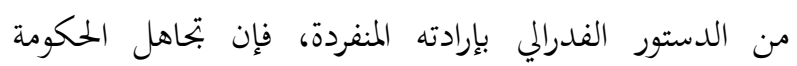

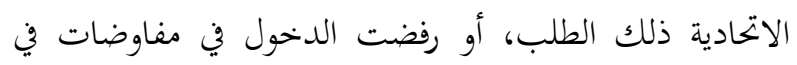

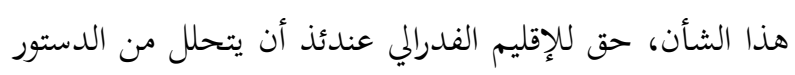

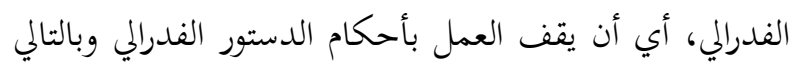
الإعلان عن ذاته دولة مستقلة.

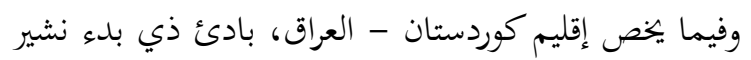

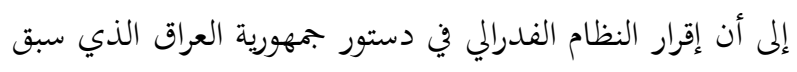

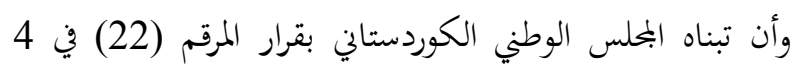

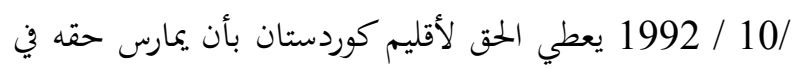

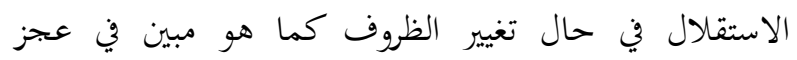
القرار:" نعلن بالإمماع قرار حق تقرير المصير وتحديد العلاقة القانونية مع الحكومة الإتحادية في هذه المرحلة على أساس القراس

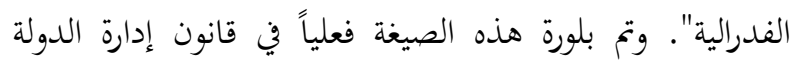

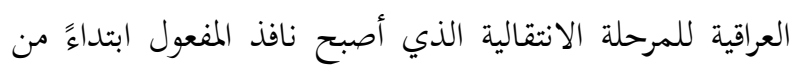

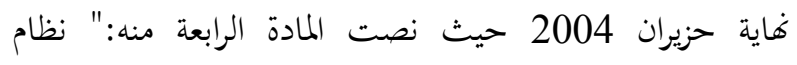

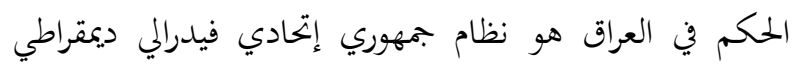
تعلدي، وييري تقاسم السلطات فيه بين الحكومة الاتحادية والحكومات الإقليمية والمحافظات والبلديات والإدارات المحلية".

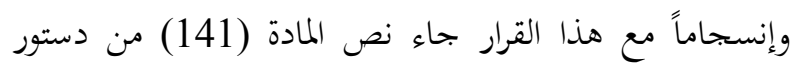

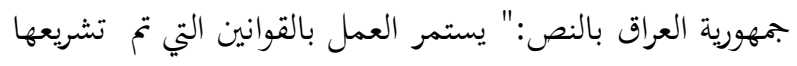

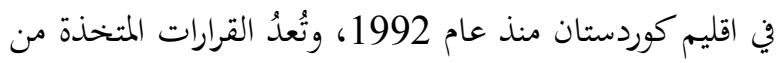

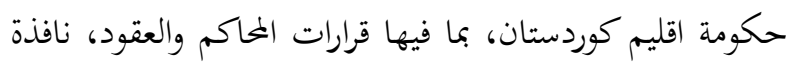

وفي 30 يونيو 2004 أعترف قانون إدارة الدولة العراقية

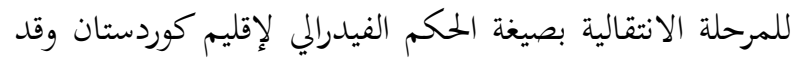
تمت إعادة تأكيد هذا المركز في الفقرة الأولى من المادة (117)

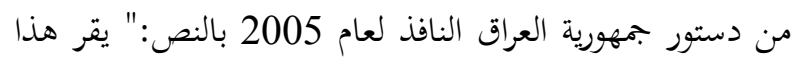
الدستور ، عند نفاذه ، إقليم كوردستان وسلطاته القائمة إقليماً

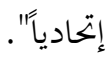

المطلب الثاني: الإطار الدستوري لصلاحية إقليم كوردستان في ممارسة حقه في الاستقلال سبق لنا القول بأن صلاحية ممارسة حق الإستقلال يختلف فئل فئل فئل

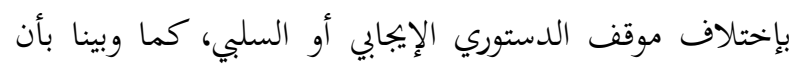

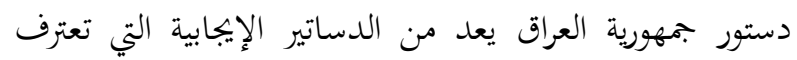

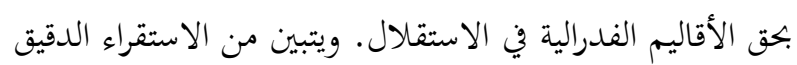
والموضوعي لدستور جمهورية العراق، بأن للإقليم الفدرالي صلاحية مارسة حقه في الاستقلال في حالتين: فلالأول منهما،

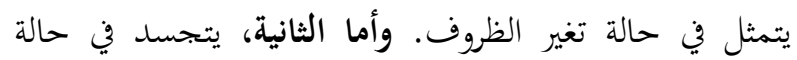
الإخلال بالدستور . ولدراستهما خخصص لكل حالة الة فرعاً مستقلاً

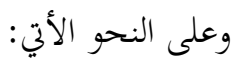
الفرع الأول: حالة تغير الظروف غني عن البيان أن الدستور الفدرالي عقد سياسي الفروف الفاسي وإجتماعي، ويعتبر الأساس القانوني لعضوية الأقاليم في الدولة العندي

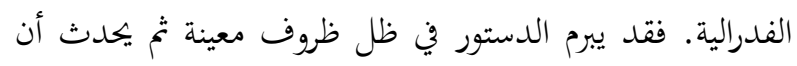

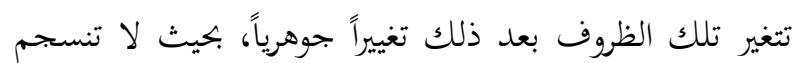
وتطلعات الأقاليم الفدرالية على نو يجعل الاستمرار بالالتزام به

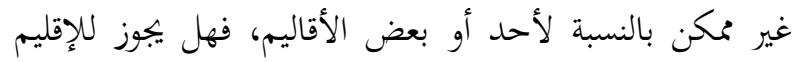

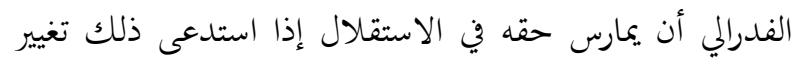
الظروف الخيطة بالدولة الفدرالية أو أحد أقاليمها الفدرالية تغييراً

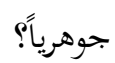
للإجحابة عن هذا السؤال يجب التميز بين حالتين: فالأولى، حالة تغيير الظروف المخيطة بالدولة الفدرالية بشكل عام لأي الئي

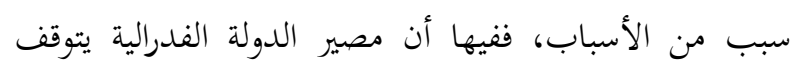

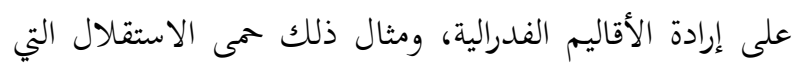


المتعلقة بحقوق الأقاليم ومن أههما:" م9، م112، م140،

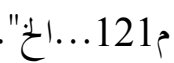

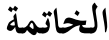

وفي الختام نوجز أهم الاستنتاجات والمقترحات، وعلى النحو

أولاً: الاستنتاجات: - الات

1. الأصل في حق الأقاليم الفدرالية في الاستقلال هو حق الق

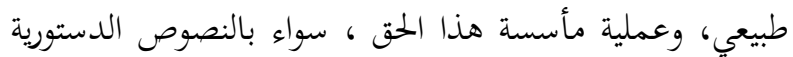
أم الدولية ، يجب أن لا تؤدي إلى مصادرته أو إهداره.

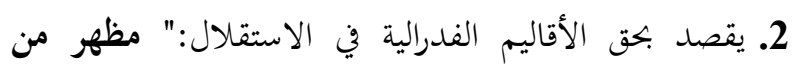
المظاهر الخارجية لحق تقرير المصير يتمتع بمقتضاه الإقليم الفدرالي بمكنة تغير طبيعة علاقته الفدرالية مع الحكومة

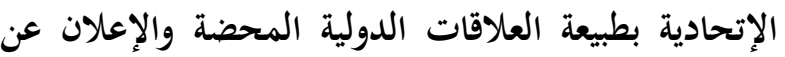
ذاته دولة مستقلة ذات سيادة كاملة؛ ذلك بالوسائل السلمية الديمقراطية ".

3. الفلسفة الأساسية من وراء حق الأقاليم الفدرالية في الاستقلال: أن يجكم الشعب نفسه بنفسه. 4. هي نظرية التوازن الدستوري الأساس الفلسفي لحق الأقاليم

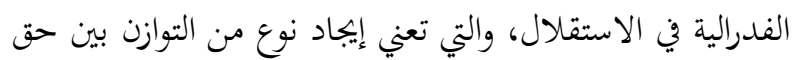

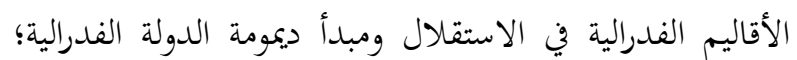
ذلك لحماية الحقوق الدستورية لكل من الحكومات الأقليمية والحكومة الإتحادية، فضلاً عن التوازن الدستوري العمودي. 5. يتنازع الدساتير الفدرالية والقضاء الدستوري والفقه الدستوري فيما يتعلق بحق الأقاليم الفدرالية في الاستقلال مواقف إيجابية وأخرى سلبية.

6. لإقليم كوردستان - جمهورية العراق صلاحية ممارسة حقه في الاستقلال في حالتين: الأولى تتمثل في حالة تغير الظروف. واما الأخرى، تتجسد في حالة عدم الإلتزام بالدستور. ثانياً: التوصيات
المفعول ما لم يتم تعديلها او الغاؤها حسب قوانين اقليم

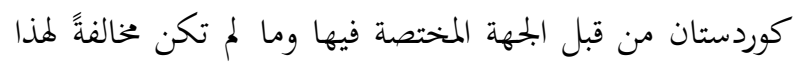

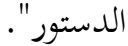
الفرع الثاني: حالة عدم الإلتزام بالدستور

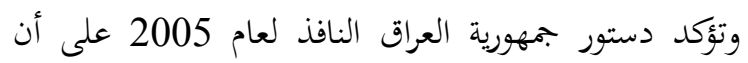

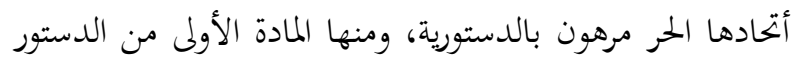
التي نصت صراحة:" جمهورية العراق دولة اتحادية...، وهذا الدستور ضامن لوحدة العراق ) وهذا يعني إن العبارة الاولى

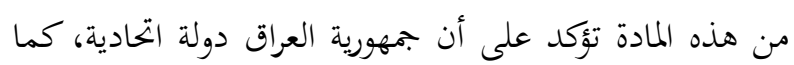

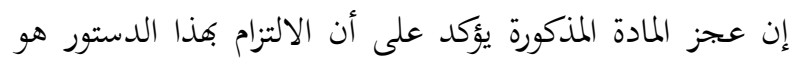

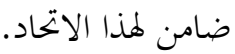
ونستنتج من ذلك أن الاتحاد الاختياري الحر الجمهورية العراق مرهون بالدستورية، وأن العديد من نصوص الدستور تلقي على عاتق رئيس الجمههورية والسلطات الاتحادية ضمان الالتزام

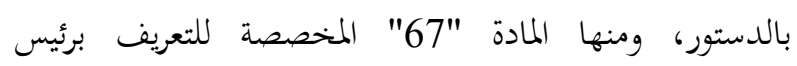

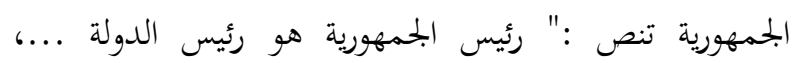
ويسهر على ضمان الالتزام بالدستور، والمحفاظة على استقلال

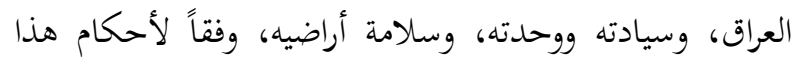

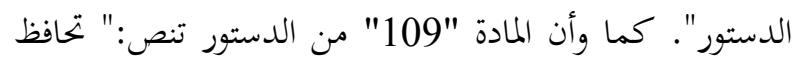
السلطات الاتحادية على وحدة العراق وسلامته واستقلاله

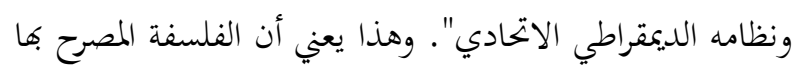

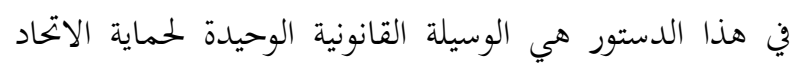
الاختياري الحر لجمهورية العراق، وهذا ما أكيد عليه عجز

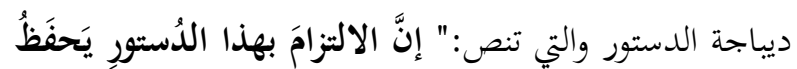

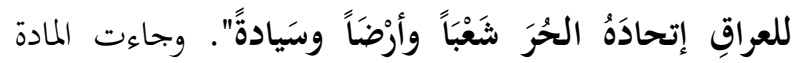

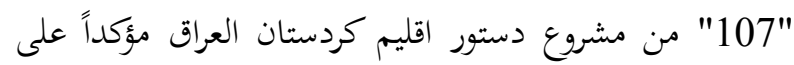

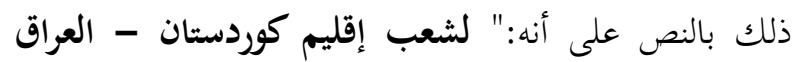
الحق في تقرير مصيره بنفسه...". ورغم صراحة النصوص المتقدمة التي تؤكد على أن السلطات الاتحادية تسهر على الالتزم

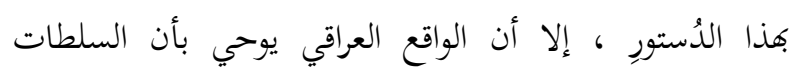

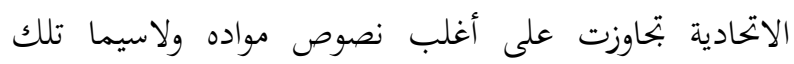


والتوزيع، بيروت، 1989، ص505. وكذلك المنجد في اللغة والإعلام،

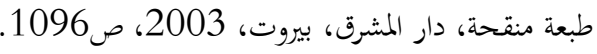

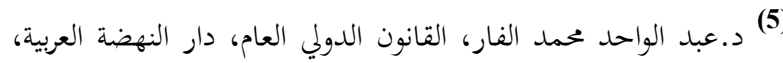

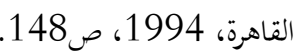

${ }^{(6)}$ Florentina Harbo, Op. Cit. p.132.

(7) ومثال ذلك إلحاق مدينة غدانسك "Gdansk"، التي كانت تحت نظام التدويل وفقاً للمادة (100) من معاهدة فرساي عام 1919، 1919، بدولة

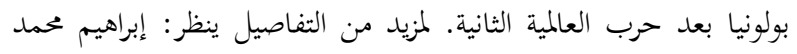

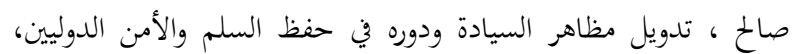

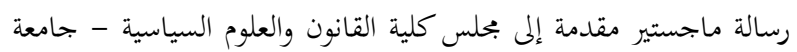

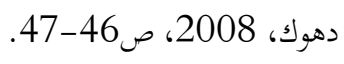

(8) ينظر: (ק2 - ف4) من ميثاق الأمم المتحدة:"يمتنع أعضاء الهيئة جميعا

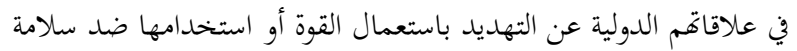

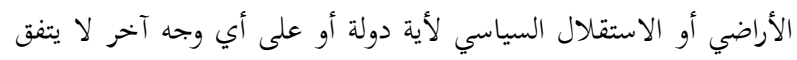

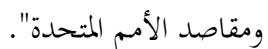
(9نظر:(م) - (9) ف20) من ميثاق الأمم المتحدة:" إنماء العلاقات الودية

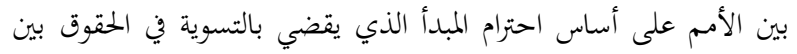

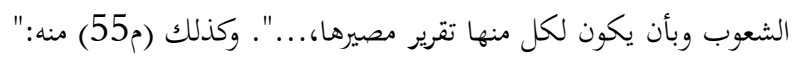
رغبة في هيئة دواعي الاستقرار ... لقيام علاقات مؤسسة على احترام المبدأ

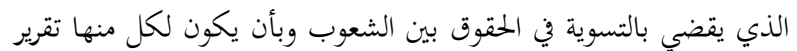

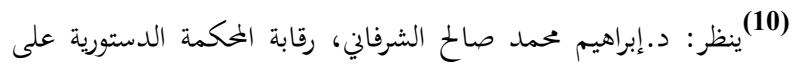

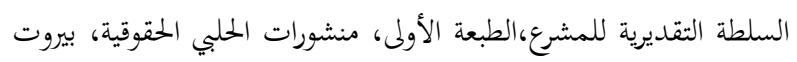
- لبنان، 2016، ص12. وكذلك د. سمير عبد السيد تناغو، النظرية

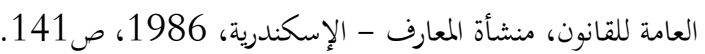

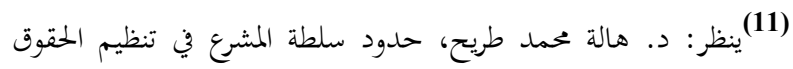

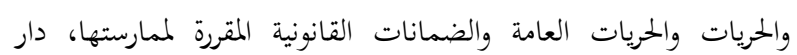

$$
\text { النهضة العربية، 2011، صلحريات العاسة والضمانات وما يعدها. }
$$

(12)(مزيد من التفاصيل ينظر: د.طارق عبدالحميد الشهوي، نظرية العقد

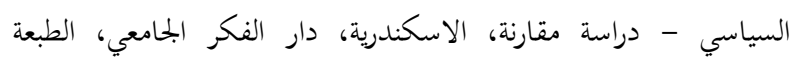

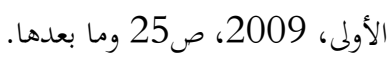

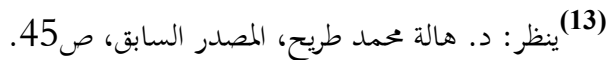

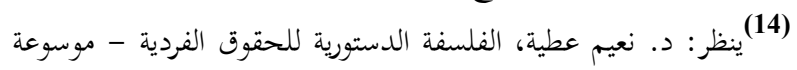

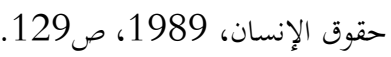

${ }^{(15)}$ William H. Riker, op. cit. P.9.

${ }^{(16)}$ David Hume:"claimed that governments were necessary, but that justification is founded on their
1. نوصي الدول الفدالية الإقرار بدستورية الممارسة المشروطة

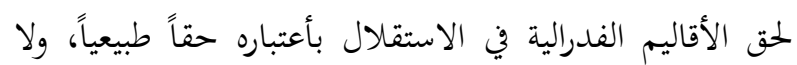

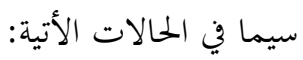

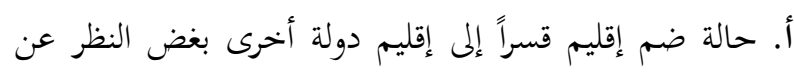
كوغها مركبة أو بسيطة. ب. حالة تغير الظروف تغيراً جوهرياً. ت. حالة عدم إلتزام الحكومة الفدرالية بالدستور وانتهاكها الجسيم لإختصاصات الأقاليم الفدرالية.

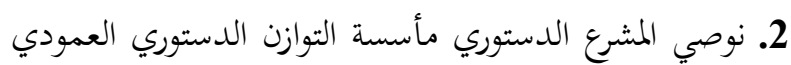

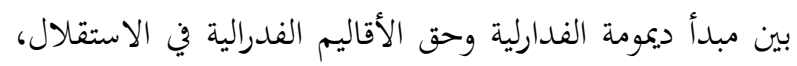
على أن لا تؤدي إلى مصادرة هذا الحق أو إهداره.

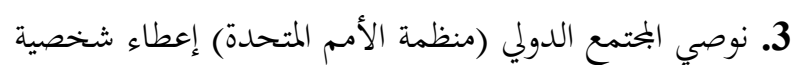

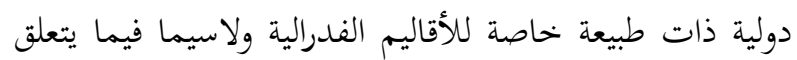
بممارسة حقه في الاستقلال؛ ذلك بغية حل المشاكل الناجمة عنها بالطرق السلمية وعلى الأخص الطرق القضائية.

(1) William H. Riker, The Development of American Federalism, Kluwer Academic Publishers, 1987, P.9. (1) (1)عبدالكريم علوان، الوسيط في القانون الدولي، مكتبة دار الثقافة للنشر

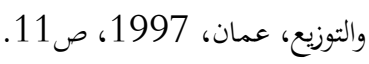
(3) ظهرت نظرية الإبطال أثناء الحرب الانفصال في الولايات المتحدة

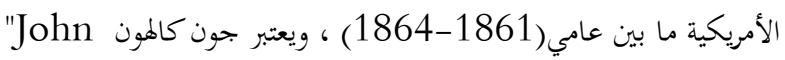

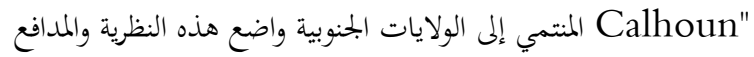

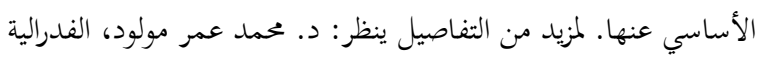

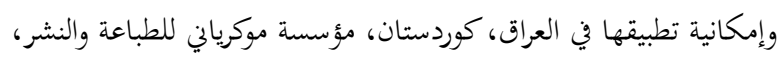

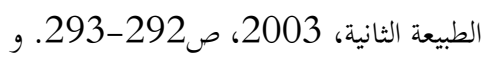

- Florentina Harbo, Secession Right - an Anti - Federal Principle, Comparative Study of Federal State and The EU, Journal of politics and Law, Norwegian Institute for Strategic Studies, Vol. 1.No. 3, September 2008, P.133.

(4) الإنفصال لغة يعني البون أي الحاجز بين الشيئين، وفصلت الشيء

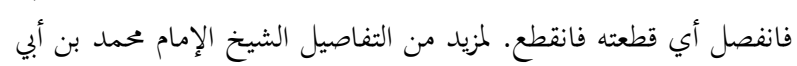

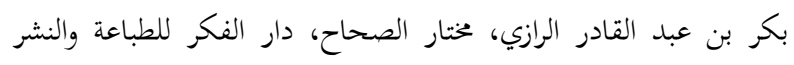


أن تحدد وبحرية مركزها السياسي وأن تسعى بحرية إلى تحقيق نمائها الاقتصاد والاجتماعي والثقافي".

(21) The right to self-determination, including secession, of every Nation, Nationality and People shall come into effect: (a) When a demand for secession has been approved by a two-thirds majority of the members of the Legislative Council of the Nation, Nationality or People concerned; (b) When the Federal Government has organized a referendum which must take place within three years from the time it received the concerned council's decision for secession; (c) When the demand for secession is supported by majority vote in the referendum; (d) When the Federal Government will have transferred its powers to the council of the Nation, Nationality or People who has voted to secede; and (e) When the division of assets is effected in a manner prescribed by law.

${ }^{\text {(22) }}$ Yugoslavia is defined as a federal republic of equal nations and nationalities, freely united on the principle of brotherhood and unity in achieving specific and common interest, with the right of nations to selfdetermination up to secession.

لم يكن بالإمكان انفصال جنوب السودان دون ترتيبات شرعية

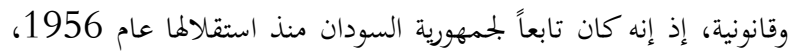
والتي تمت من خلال اتفاق طرفي النزاع " الحكومة السودانية - والحركة الشعبية لتحرير السودان" على اتفاقية السلام التي تم التوقيع عليها في العاصمة الكينية "نيروبي" في 2005، وبموجب هذه الاتفاقية تم اعتماد دستور انتقالي للسودان منح الجنوبيين الحق في تقرير مصيرهم عبر استفتاء يتم بعد ستة سنوات من بداية المرحلة الانتقالية، وتم إجرائه في 2011 وبموجبه تم استقلال جنوب السودان.

(24) المادة (2) من دستور المكسيك الصادر عام 1917 شاملاً تعديلاته لغاية عام 2007.

(25) المادة (1) من دستور جمهورية البرازيل الصادر عام 1988 شاملاً تعديلاته لغاية عام 2015.

(26) المادة (2) من دستور إسبانيا الصادر عام 1978 شاملاً تعديلاته لغاية عام 2011. (27) المادة (22) من دستور جمهورية الأرجنتين الصادر عام 1983 شاملاً تعديلاته لغاية عام 1994. (28) (المصدر نفسه.

(29)عدت محكمة العدل الدولية في العديد من آرائها الاستشارية مبدأ الحق نقاً

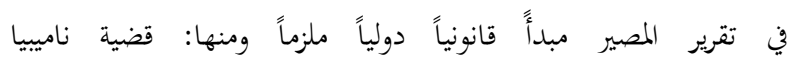

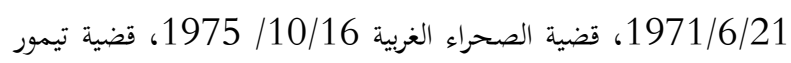
الشرقية في 1995/6/30، وجاء رأي المحكمة في معرض تعقيبها على ability to produce a greater happiness than would be found without them".

${ }^{(17)} \mathrm{We}$ the people of the United States, in order to form a more perfect union, establish justice, insure domestic tranquility, provide for the common defense, promote the general welfare, and secure the blessing of liberty to ourselves and our posterity, do ordain and establish this constitution for the United State of American.

${ }^{(\mathbf{1 8})}$ Florentina Harbo, Op. Cit. p.133.

${ }^{(19)}$ Op. Cit. p.133.

(20)

التي سادت فيها مفاهيم سلطة الشعب التي رافقت الثورتين الأمريكية 1776 والفرنسية 1789، بهدف تمكين الشعوب من التخلص من فئن الأنظمة الاستبدادية، فتبنت الثورة الفرنسية هذا الحق في إطار المبادئ التي وردت في المرسوم الذي أصدرته الجمعية الوطنية الفرنسية في 19 تشرين الثاني 1792 ، الذي أكدت فيه مساندتا للشعوب المطالبة بالاستقلال وممايتها للمناضلين الذين يكافحون من أجل الحربة. وذكره الرئيس الأمريكي "مونرو" في العام 1823 في سياق رفضه التدخل الأجنبي وتحديداً الأوروبي في شؤون بلاده الداخلية، وجاءت فيما بعد الفقرة الخامسة من مقترحات الرئيس الأمريكي "ويلسون" التي أعلنها في 8 كانون الثاني 1918 لتسوية أوضاع شعوب الأقاليم الواقعة تحت هيمنة قوى الترئيس أجنبية ناصاً على هذا المبدأ، قائلاً في رسالة أرسلها للكونغرس الأمريكي:" إحتراماً للمطامح القومية وحق الشعوب في ألا تُحكم إلا بإرادما، وأن هذا الحق ليس بجرد تعبير بل هو مبدأ ضروري للعمل". ويعد حق تقرير المصير من المبادئ المستقرة في القانون الدولي، فأشارت

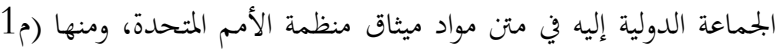
-ف2) والمادة (55). وتعززت تلك المكانة القانونية بإدراجه في المواثيق الدولية، ومثال ذلك المادة الأولى من العهدين الدوليين للحقوق المدنية والسياسية وللحقوق الاقتصادية والاجتماعية والثقافية الصادرين في عام

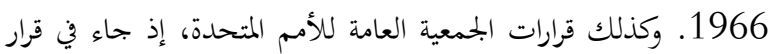
الجمعية العامة للأمم المتحدة رقم (1514) الصادر في كانون الأول 1960 المتضمن إعلان منح الاستقلال للشعوب والبلدان المستعمرة أنه:" لجميع الشعوب الحق في تقرير مصيرها، ولما بمقتضى هذا الحق أن تحدد بحرية مركزها السياسي وتسعى بحرية إلى تحقيق إنمائها الاقتصادي والاجتماعي والثقافي". وقرار الجمعية العامة للأمم المتحدة المرقم (2625) لعام 1970 والمتعلق بالعلاقات الودية بين الدول قد أقر منح حق تقرير إمعير المصير. كما وجاء في الإعلان الصادر عن المؤتمر العالمي لحقوق الإنسان الذي عقد في فيينا بإشراف الأمم في المدة 14- 25 حزيران 1993

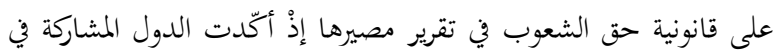

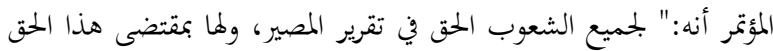


باعتبارها طرفاً في الاتفاق الدستوري". لمزيد من التفاصيل ينظر : د. ميشال

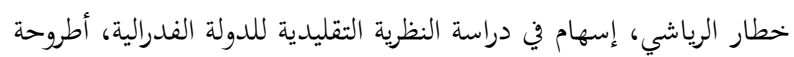

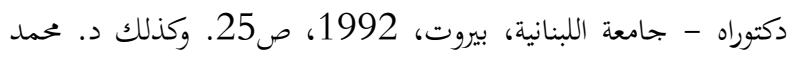

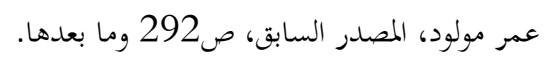
(35) محمد الهماوندى، الحكم الذاتي الفيدرالي والنظم اللامركزية الإدارية والسياسية - دراسة نظرية مقارنة، الطبعة الأولى، دار المستقبل العربي،القاهرة، 1990، صبية ص187. (36)د. الشافعي محمد بشير، نظرية الاتحاد بين الدول وتطبيقها بين الدول العربية، رسالة دكتوراه، كلية الحقوق - جامعة الأسكندرية، 1963، بطنية، ص صع (37) (37)محد يعقوب عبدالرمن، التدخل الإنساني في العلاقات الدولية، الطبعة الأولى، مركز الإمارات للدراسات والبحوث الاستراتيجية، أبو ظبي . دولة الإمارات العربية المتحدة، 2004، صردو الإسات 199. (38)(معاهدة سيفر هي معاهدة السلام التي تم التوقيع عليها في 10

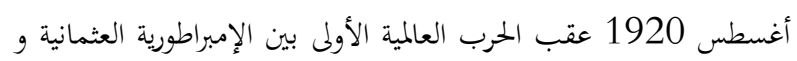
قوات الحلفاء ولكن المعاهدة رفضت من قبل الحركة القومية التركية بزعامة مصطفى كمال أتاتورك التي شكلت جمهورية تركيا في 29 أكتوبر 1923 على أنقاض الإمبراطورية العثمانية. كان رفض أتاتورك لتطبيق بنود المعاهدة

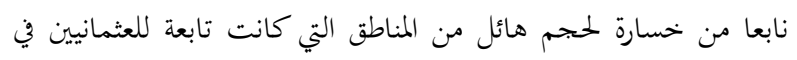
حالة تطبيق المعاهدة. كانت المعاهدة تنص على: • حصول منطقة الحجاز على الإستقلال. • حصول أرمينيا على الإستقلال. • حصول كردستان على الإستقلال حسب البندين 62 و 63 و 64 من الإنسلال

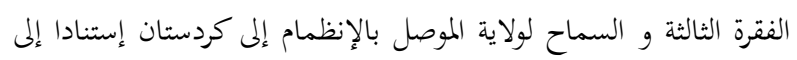
البند 62 ونصه "إذا حدث، خلال سنة من تصديق هذه الاتفاقية أن

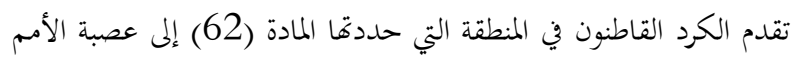
قائلين أن غالبية سكان هذه المنطقة ينشدون الإستقلال عن تركيا، وفي

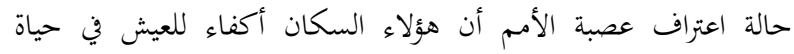
مستقلة وتوصيتها بمنح هذا الإستقلال، فإن تركيا تتعهد بقبول هذه التوصية وتتخلى عن كل حق في هذه المنطقة. وستكون الإجراءات التفصيلية لتخلي تركيا عن هذه الحقوق موضوعا لإتفاقية منفصلة تعقد بين

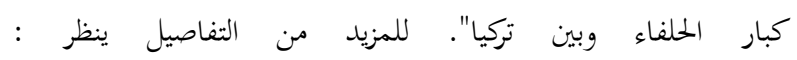
http://ar.wikipedia.org

(39) عبدالرقيب يوسف، حدود كوردستان الجنوبية تأريخياً وجفرافياً . خلال خمسة آلاف عام وما ترتب على إلحاقها بالعراق، الطبعة الأولى، مطبعة

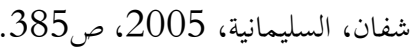

موقف البرتغال المؤيد لحق سكان تيمور الشرقية في تقرير المصير فيما يتصل

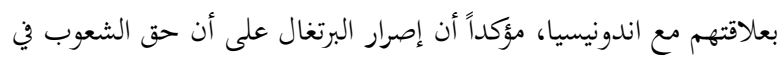

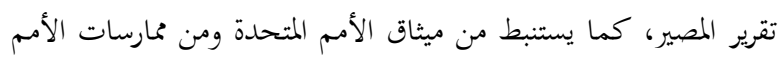

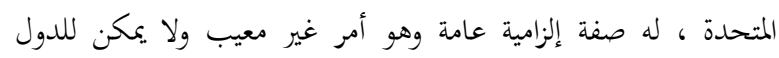

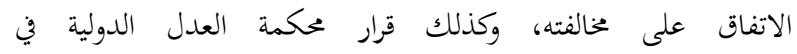
2010/7/22 الذي عَدَّ أن إعلان كوسوفو المنفرد الاستقلال عن صربيا في عام 2008 لمُ ينتهك القانون الدولي، إذذ أورد القاضي "هيساشي أوادا" رئيس المحكمة في منطوق الحكم:" أن المحكمة ترى أن القانون الدولي

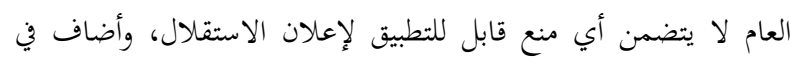

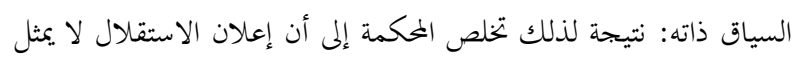

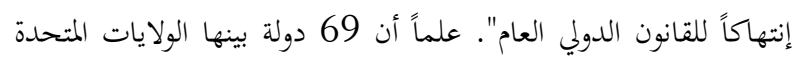
الأمريكية، فضلاً عن 22 دولة من دول الاتحاد الأوروبي قد اعترفت

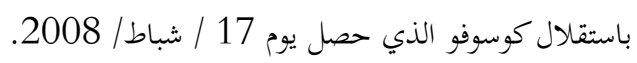
(30) م.حمد عمر مولود، المصدر السابق، ص257.

(31) the Serbian population in Bosnia and Herzegovina and Croatia is entitled to all the rights concerned to minorities and ethnic groups and that the Republics must afford the members of those minorities and ethnic groups all the human rights and fundamental freedoms recognized in international law, including, where appropriate, the right to choose their nationality". See: James Crawford, State practice and International Law in relation to Unilateral Secession, Report to Government of Canada Concerned Unilateral secession of Quebec, 19 February 1997, para61,p20.

${ }^{(32)}$ The Reference asked three questions:

1. Under the Constitution of Canada, can [a province secede] from Canada unilaterally?

2. Does international law give [a province] the right to [secede] from Canada unilaterally?

3. In the event of a conflict between domestic and international law on the right of a province to secede from Canada unilaterally, which would take precedence in Canada? see: Reference re Secession of Quebec, [1998] 2 S.C.R. 217.

- د. معمر مهدي الكبيسي، توزيع الاختصاصات الدستورية في الدولة الفدرالية - دراسة مقارنة، منشورات الحلبي الحقوقية، الطبيعة الأولى،

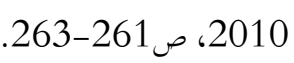

- Florentina Harbo, Op. Cit p. 133.

(34)فالأساس القانوني الذي استند عليه "Calhoun" في نظريته المعروفة ب"نظرية الإبطال" التي ظهرت أثناء حرب الأنفصال في الولايات المتحدة

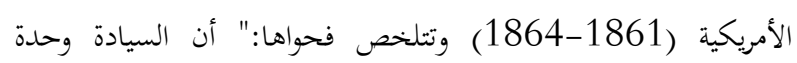
واحدة غير قابلة للتنازل والتجزئة و تكون كامنة في الدول الأعضاء 
وعا48) للمزيد من التفصيل ينظر: عبدالفتاح عبدالرزاق، مبدأ عدم التدخل وعدم التدخل في القانون الدولي العام ، الطبعة الأولى، مؤسسة موكرياني

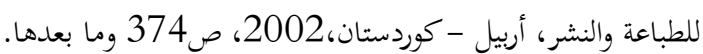

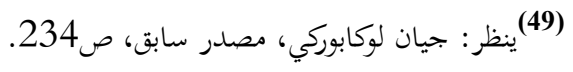

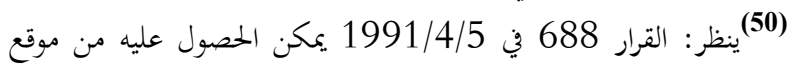
الأمم المتحدة على الانترنت:http//:www.un.org (51) ينظر : د.عبد الفتاح عبد الرزاق، مصدر سابق، ص423.

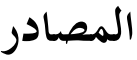

- المصادر باللغة العربية أولاً: معاجم اللغة

- المنجد في اللغة والإعلام، طبعة منقحة، دار المشرق، بيروت، 2003.

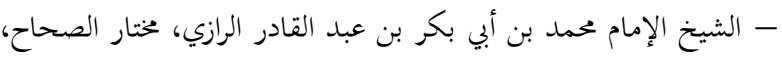

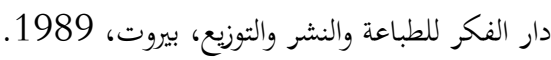

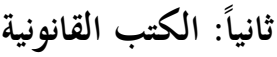

- إبراهيم محمد صالح، تدويل مظاهر السيادة ودوره في حفظ السلم والأمن الدوليين، رسالة ماجستير مقدمة إلى بحلس كلية القانون

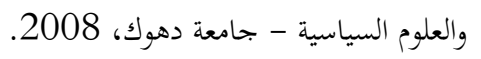

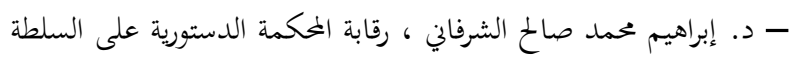

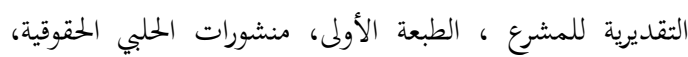

$$
\text { بيروت - لبنان، } 2016 .
$$

- د. سمير عبد السيد تناغو، النظرية العامة للقانون، منشأة المعارف -

$$
\text { الإسكندرية، } 1986 .
$$

- د. الشافعي محمد بشير، نظرية الاتحاد بين الدول وتطبيقها بين الدول

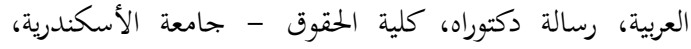

$$
.1963
$$

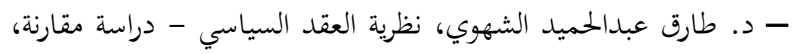
الاسكندرية، دار الفكر الجامعي، الطبعة الأولى، 2009.

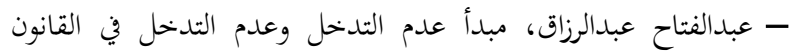

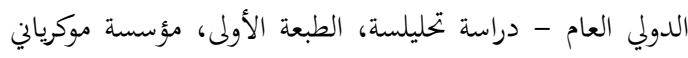

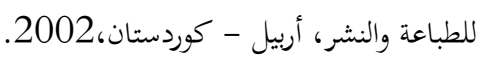

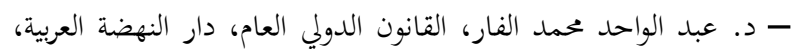

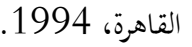

(40) وبتدر الإشارة هنا إلى أن القضية الكوردية تثير القلق السياسي للدول

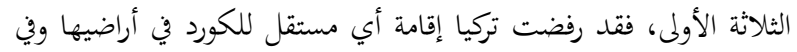

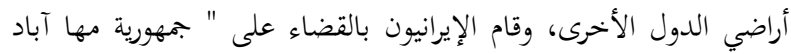

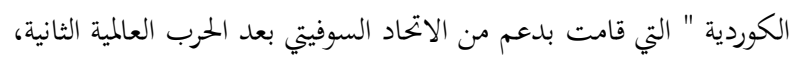

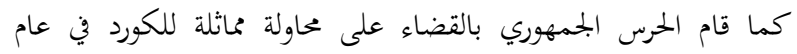
1979، أما العراق فيرفض تشكيل دولة كوردية المناطق الشمالية منه، وهكذا تجمع الدول الثلاث على محاصرة القضية الكوردية وترفض الإقرار

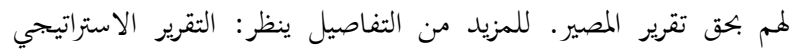

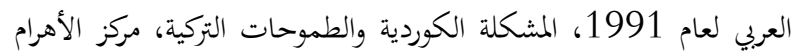

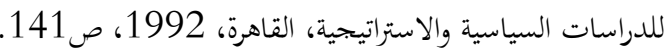

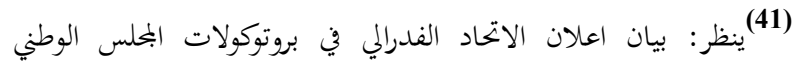

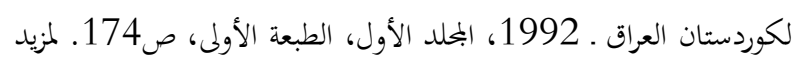

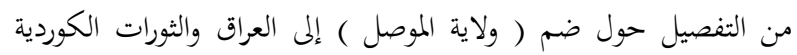

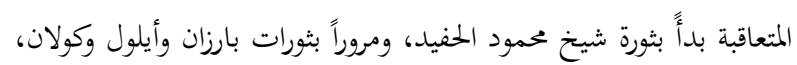

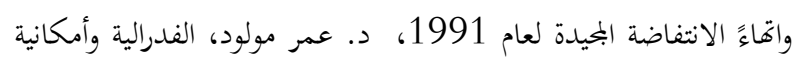

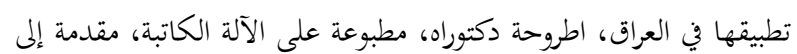

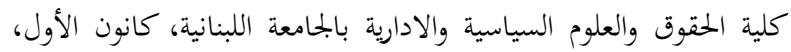
1999، صلو 7 وما بعدها.

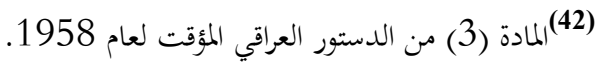

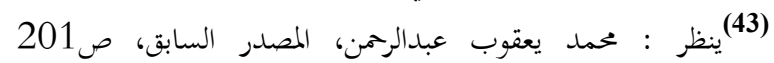

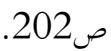
(44) حول تعريف الكورد كجماعة أثنية انظر: انظر: هشام داود، الاثنية

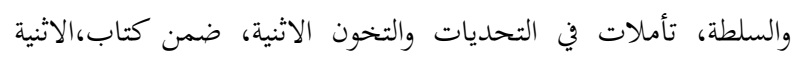
والدولة والاكراد في العراق وإيران وتركيا، الطبعة الثانية، ترجمة عبدالإله

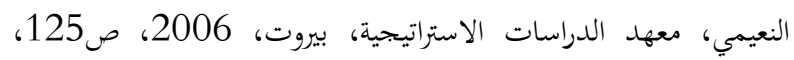
حيث يعرف الجماعات الاثنية بأها تلك الجماعات البشرية المؤمنة أماناً

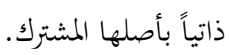

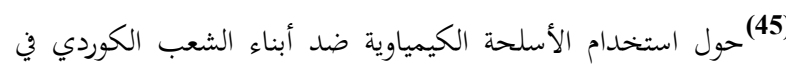

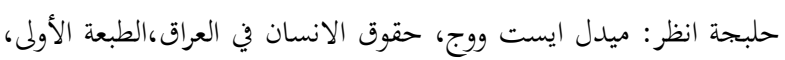

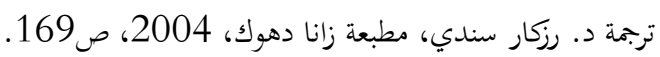
(46ينظر: بيان اعلان الاتحاد الفدرالي الذي اقره البحلس الوطني لإقليم

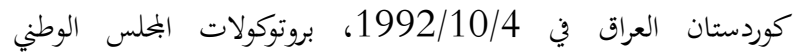

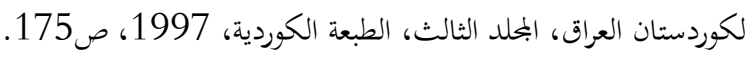

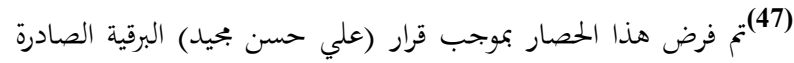
منه والمرقمة 2950/38 في 1987/6/3. 
- قرار الجمعية العامة للأمم المتحدة رقم (1514) الصادر في كانون

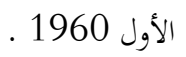

- قرار الجمعية العامة للأمم المتحدة المرقم (2625) لعام 1970.

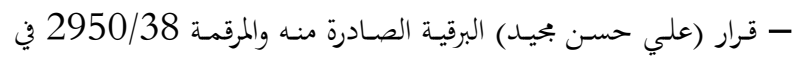
.1987/6/3

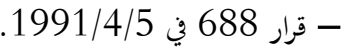
- قرار محكمة العدل الدولية في 2010/7/22 .

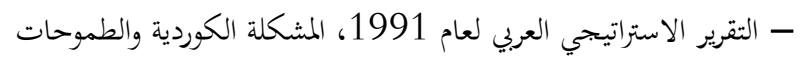

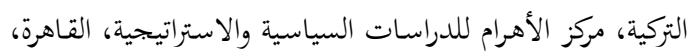

- اعلان الاتحاد الفدرالي في بروتوكولات البحلس الوطني لكوردستان العراق

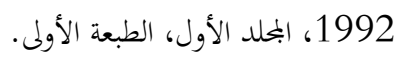

- اعلان الاتحاد الفدرالي الذي اقره البحلس الوطني لإقليم كوردستان العراق العاق العال

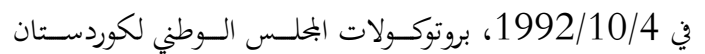

العراق، البحلد الثالث، الطبعة الكوردية، 1997. - إعلان المؤتمر العلمي لحقوق الإنسان (14- 25 / حزيران/1993 الطعة الكردة، 1997 ).

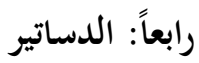
- الدستور العراقي المؤقت لعام 1958.

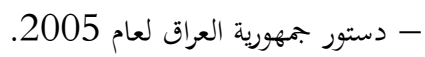
- دستور جمهورية المكسيك لعام 1917. - دستور جمهورية البرازيل لعام 1988. - دستور جمهورية إسبانيا لعام 1978. - دستور جمهورية الأرجنتين لعام 1853 ، أعيد العمل به عام 1983 ، 1983

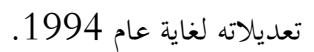

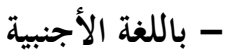

\section{First: Books}

- Florentina Harbo, Secession Right - an Anti - Federal Principle, Comparative Study of Federal State and The EU, Journal of politics and Law, Norwegian Institute for Strategic Studies, Vol. 1.No. 3, September 2008.

- James Crawford, State practice and International Law in relation to Unilateral Secession, Report to Government of Canada Concerned Unilateral secession of Quebec, 19 February 1997.

- William H. Riker, The Development of American Federalism, Kluwer Academic Publishers, 1987.

\section{Second: Decisions}

- Reference re Secession of Quebec, [1998] 2 S.C.R. 217.
- د. عبدالرقيب يوسف، حدود كوردستان الجنوبية تأريخياً وجفرافياً . خلال خمسة آلاف عام وما ترتب على إلحاقها بالعراق، الطبعة الأولى، مطبعة شفان، السليمانية، 2005.

- د. عبدالكريم علوان، الوسيط في القانون الدولي، مكتبة دار الثقافة للنشر والتوزيع، عمان، 1997. - د. عمر مولود، الفدرالية وأمكانية تطبيقها في العراق، اطروحة دكتوراه، مطبوعة على الآلة الكاتبة، مقدمة إلى كلية الحقوق والعلوم

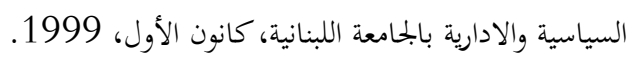
- د.محمد الهماوندى، الحكم الذاتي الفيدرالي والنظم اللامركزية الإدارية والسياسية - دراسة نظرية مقارنة، الطبعة الأولى، دار المستقبل

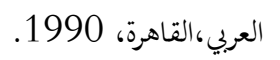

- د. محمد عمر مولود، الفدرالية وإمكانية تطبيقها في العراق، كوردستان، مؤسسة موكرياني للطباعة والنشر، الطبيعة الثانية، 2003. - د. محمد يعقوب عبدالرحمن، التدخل الإنساني في العلاقات الدولية، الطبعة الأولى، مركز الإمارات للدراسات والبحوث الاستراتيجية، أبو ظبي ـ دولة الإمارات العربية المتحدة، 2004.

- د. معمر مهدي الكبيسي، توزيع الاختصاصات الدستورية في الدولة الفدرالية - دراسة مقارنة، منشورات الحلبي الحقوقية، الطبيعة

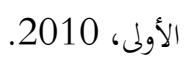

- د. ميدل ايست ووج، حقوق الانسان في العراق،الطبعة الأولى، ترجمة د. رزكار سندي، مطبعة زانا دهوك، 2004.

- ميشال خطار الرياشي، إسهام في دراسة النظرية التقليدية للدولة الفدرالية، أطروحة دكتوراه - جامعة اللبنانية، بيروت، 1992. - د. نعيم عطية، الفلسفة الدستورية للحقوق الفردية - موسوعة حقوق برون الإنسان، 1989.

- د. هالة محمد طريح، حدود سلطة المشرع في تنظيم الحقوق والحريات والحريات العامة والضمانات القانونية المقررة لممارستها، دار

$$
\text { النهضة العربية، 2011، صلون } 45 \text { وما يعدها. }
$$

- د. هشام داود، الاثنية والسلطة، تأملات في التحديات والتخون الاثنية، ضمن كتاب،الاثنية والدولة والاكراد في العراق وإيران

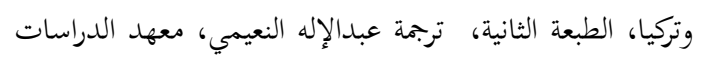
الاستراتيجية، بيروت، 2006.

ثالثاً: الوثائق والمعاهدات الإعلانات والقرارات الدولية

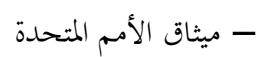
ــ معاهـدة سـيفر هـي معاهـدة السـلام الستي تم التوقيـع عليهـا في 10 في 1020 أغسطس 1920. 
مافى هه يُمين فيدرال د سهربهخوهبونيّ دا - هه ريّما كوردستاني نمونه

يوخته

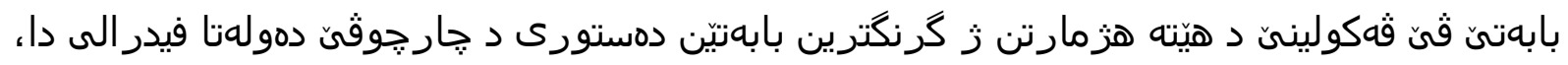

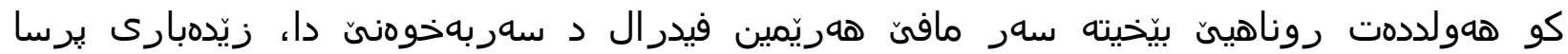

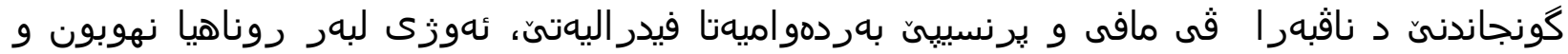

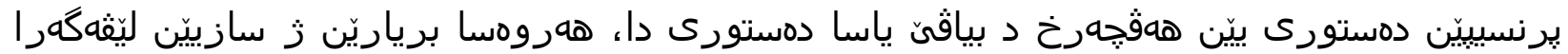
دادوهريا دهستورى دمرئيّيخ دهستين.

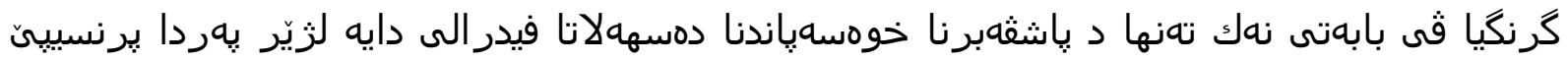

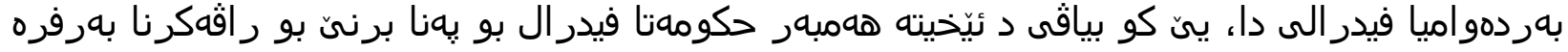

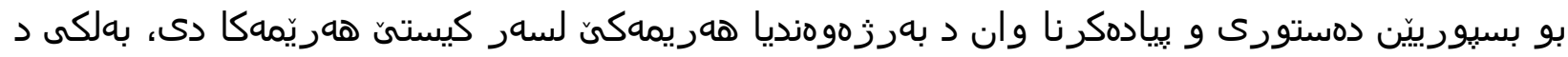

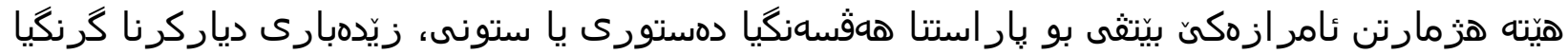

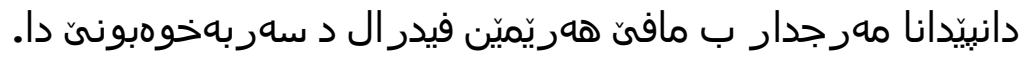

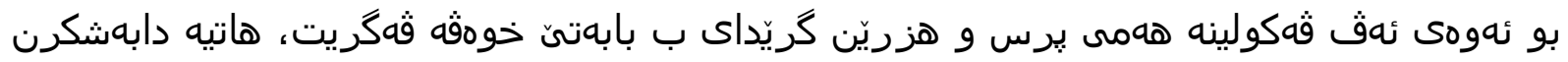

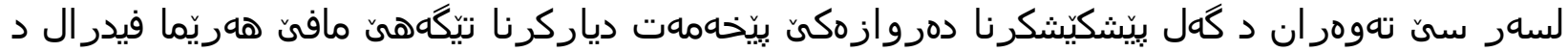

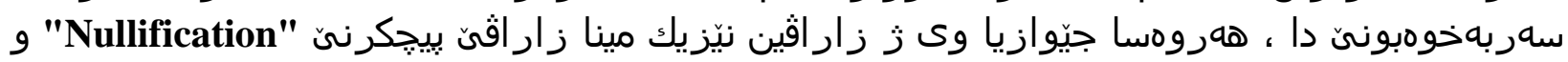

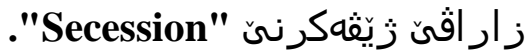

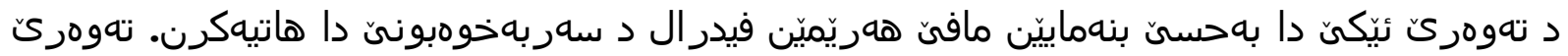

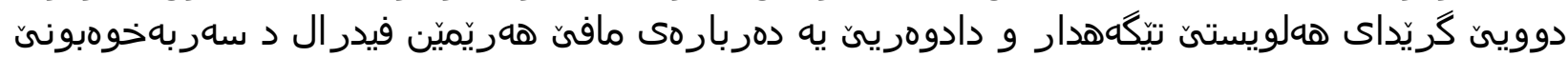

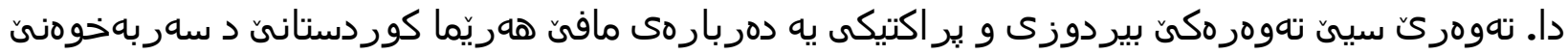

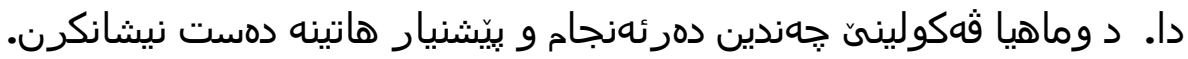




\title{
THE RIGHT OF FEDERAL REGIONS TO INDEPENDENCE
}

\begin{abstract}
The topic of our study is considered a very critical constitutional issue within the framework of the federal state. The study is an effort to shed light on the right of federal regions to independence as well as the issue of creating a sort of compromise between such a right and the principle of federalism sustainability in the light of the currently emerging developments and principles in the field of comparative constitutional law in addition to the provisions of the judgments passed by the institutions of Constitutional and Judicial review.

The significance of this subject does not simply lie in the principle of its being a counter solution in the face of the federal authority's tyranny under the guise of the principle of federalism sustainability which allows the federal government to resort to a broad interpretation of the constitutional competencies and practice a kind of favoritism in favor of one region at the expense of another. It is rather an essential tool to maintain the vertical constitutional balance, as well as the need for conditional recognition of the right of federal regions to independence.

To ensure that the study covers all matters and ideas relevant to its topic, I have divided it into three chapters with an introductory section for the objective of clarifying the concept of federal regions to independence and distinguishing it from the other confusing concepts among which are some common overlapping terms such as "Nullification" and the term of "Secession".

In the first chapter, I have discussed the basis of the right of the federal regions to independence (the philosophical basis, the legal basis). While in the second chapter, I have covered the point of view of jurisprudence and the judiciary regarding the right of the federal regions to independence. As for the third chapter, it is rather a theoretical and practical topic that demonstrates the legality of the right of Kurdistan Region to independence. Finally, I have ended the study with a concluding section where I have stated the conclusions that $I$ have reached in the course of the study and have also included some recommendations.
\end{abstract}

